Est Ag 39 (2004) 445-478

\title{
La muerte de Pedro y Pablo en Roma
}

Sin lugar a dudas, Pedro y Pablo son dos de las personalidades más importantes de la iglesia primitiva. Conocemos los nombres de otros misioneros o dirigentes de los primeros años después de Pascua, pero ninguno logró una posición tan relevante en los escritos primitivos cristianos y, sin lugar a dudas, ninguno influyó tanto en la tradición litúrgica ni en la historia de la iglesia. Con la Reforma luterana se convirtieron ambos apóstoles en banderas confesionales: Pedro como imagen del papado católico y Pablo como símbolo de la reforma. Esta confrontación alcanza su punto culminante con la presentación del cristianismo primitivo propuesta por Baur, para quien el cristianismo primitivo estaba formado por dos grupos confrontados, los judeo- y los pagano-cristianos, con Pedro y Pablo a la cabeza de cada grupo. Esas posturas confesionales se han acercado en la actualidad, como demuestran los estudios exegéticos y dogmáticos ${ }^{1}$.

En contadas ocasiones, estos dos apóstoles estuvieron en contacto directo. Sabemos que después de su conversión, Pablo sube a Jerusalén y se encuentra con Pedro durante un periodo breve de tiempo (Gal 1,18s). Pasarán unos años hasta que vuelvan a verse en el sínodo de Jerusalén (Gal 2,1-10 y Hech 15). Poco tiempo después, el conflicto de Antioquía marcará significativamente sus relaciones posteriores (Gal 2,11-21). En esta ocasión, Pablo salió perdedor en la confrontación, por lo que tuvo que abandonar la comunidad de Antioquía y comenzar su misión independiente. Pedro permaneció en estrecha relación con Antioquía, donde posiblemente actuó como dirigente de esa comunidad. Seguramente tenían noticias indirectas uno de otro. Pablo menciona en contadas ocasiones la figura de Pedro en cartas posteriores. En 1. Cor menciona el "partido de Pedro" (1Cor 1,10-3,23), la actividad misione-

1. H. Lietzmann, Petrus und Paulus in Rom. Liturgische und archäologische Studien (AKG 1), Berlin 19272; O. Cullmann, Petrus. Jünger - Apostel - Märtyrer. Das historische und das teologische Petrusproblem, Zürich 19853. Para una visión de las posturas de los exégetas modernos véase, Lothar WeHr, Petrus und Paulus - Kontrahenten und Partner. Die beiden Apostel im Spiegel des Neuen Testaments, der Apostolischen Väter und früher Zeugnisse ihrer Verehrung (Neutestamentliche Abhandlungen N.F. 30), Aschendorff, Münster 1996, 4-27; Christfried BÖTTRICH, Petrus. Fischer, Fels und Funktionär (Biblische Gestanten 2), Leipzig, Evangelische Verlagsantalt 2001, 262-277. 
ra de Pedro con su mujer (1 Cor 9,15$)$ y la aparición del Maestro a Pedro (1Cor 15,1-11). Ningún otro escrito neotestamentario relaciona las dos personalidades. Los escritos y tradiciones posteriores de los siglos II-IV (Padres de la Iglesia, escritos apócrifos, la tradición y la liturgia), los volverán a relacionar: les atribuyen una actividad misionera y la muerte de ambos en Roma. Estos escritos tienden a asociar a Pedro y Pablo hasta formar una especie de entidad simbólica del apostolado total, a ocultar sus diferencias y a hacerlos columnas apostólicas ${ }^{2}$ de la Iglesia. Los dos apóstoles no podían ser separados porque se habían convertido en una sola cosa en la fundación de la Iglesia de Roma.

La idea que nos intentan transmitir las fuentes es la inseparabilidad de los dos apóstoles en Roma. ¿Pero fue esto una realidad en vida de los apóstoles o más bien una creación de la comunidad romana? Después de la expulsión de los "judíos" por parte del emperador Claudio (Hech 18,2), entre los que se encontraban Áquila y Priscila, la comunidad de Roma se distancia de la sinagoga y, por tanto, adquieren más importancia los pagano-cristianos. La carta a los Romanos es un testimonio indirecto de tal situación. Es decir, se aceptaría en Roma la estrategia misionera paulina y, con su visita, se convertiría en una "comunidad filopaulina" según el acuerdo alcanzado en el sínodo de Jerusalén. No obstante, la tradición ha desbancado, en parte, a Pablo en favor de la figura petrina. ¿A qué se debió? Es objeto de este artículo intentar explicar por qué hubo corrientes tempranas "romanas" que resaltaron la figura de Pedro sobre la de Pablo. En la época en que se redacta la 2 Pedr, Pedro incluso comenzaba a ganarle terreno a Pablo $^{3}$. Esta tendencia tiene tal vez una explicación histórica. Pedro tuvo que tener una relación o relevancia especial en dicha comunidad, incluso superior a Pablo para llegar a alcanzar esa posición privilegiada.

\section{Los orígenes del cristianismo en Roma}

"Todos los caminos conducen a Roma". Este es un dicho popular, que ante todo tenía validez en el siglo primero de nuestra era. La capital del imperio, como centro económico, cultural y político de la época, atrajo a muchas personas de diversas culturas y religiones. El judaísmo no fue una excepción. También el cristianismo primitivo llegó a la capital como grupo judío. La sina-

2. Véase p.e. el epigrama del papa Dámaso (366-384), Epigr. 26: cf. R. Brändle, "Petrus und Paulus als nova sidera", en: Teologische Zeitschrift 27 (1992) 207-215.

3. Saint Pierre dans le Nouveau Testament (Coll Lectio divina 79), Paris 1974, 191-192. 
goga fue en Roma, como había sucedido también en Grecia, el lugar por excelencia donde los cristianos llevaron a cabo su labor misionera y el punto de partida para la formación de la comunidad cristiana. Todo hace suponer que la comunidad cristiana de Roma tuvo su origen en ambientes y círculos del judaísmo romano. De otro modo no se explicaría la expulsión de algunos judíos y cristianos en el año 49 mediante el edicto del emperador Claudio ocasionado por el conflicto interno, dentro del judaísmo romano, entre judíos y judeocristianos 4 .

El testimonio literario más antiguo de la presencia de cristianos en Roma

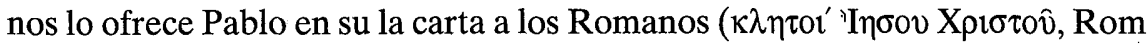
1,6). Esta comunidad existía antes de su llegada y, por tanto, él no la pudo fundar. Es de suponer que ninguno de sus colaboradores la fundó, pues Pablo lo habría mencionado en la carta ${ }^{5}$. Una antigua tradición cristiana vincula la iglesia de Roma con la figura del apóstol Pedro. Éste es el único apóstol que la tradición cristiana asocia a dicha ciudad e incluso, como después veremos, en algunas fuentes viene considerado como el primer "episkopos" de Roma (Ireneo, $a d v$. III 1,1; 3,2; Eusebio, HE II 14,6), aunque no especifican el contenido del término. Esta función la desempeñaría Pedro durante veinticinco años ${ }^{6}$. La indicación lucana (Hech 12,17) de que Pedro abandonó Jerusalén a inicios de los años cuarenta y se fue a otro lugar, alberga la remota posibili$\operatorname{dad}^{7}$ de que se trasladara a Roma ${ }^{8}$. Ciertos autores buscan los orígenes de la

4. Cf. I. LevinskAYA, Book of Acts in its First Century Setting. Vol. 5: The Book of Acts in Its Diaspora Setting, Grand Rapids, Mich - Carlisle 1996, 167-193.

5. F. WATSON, "The Two Roman Congregations: Roman 14:1-15:13", in: K.P. DONFRIED (ed.), The Romans Debate, Edinburgh 1991, 210s., presupone que Andrónico y Junia (Rom 16,7) fueron los fundadores del cristianismo en Roma.

6. JERÓNIMO, De viris illustribus 8; Eusebio, HE II,14,6; II,15,2.

7. H. Botermann, Das Judenedikt des Kaisers Claudius, Franz Steiner Verlag, Stuttgart 1996, 137-140. Véase J.W. WenhaM, "Did Peter go to Rome in A.D. 42?", in: TynB 23 (1972) 94102. C.P. Thiede, Geheimakte Petrus. Auf den Spuren des Apostels, Kreuz, Stuttgart 2000, identifica el lugar desconocido de Hech 12,17 con Roma, y justifica este silencio de Lucas: "Lukas, der noch zu Lebzeiten des Petrus für einen einflussreichen Römer schreibt, hütet sich davor, Theophilus dadurch in Verlegenheit zu bringen, dass er ihm mitteilt, wohin jener Mann gegangen war, der sich der von den Römern eingesetzten Staatsgewalt durch Flucht entzogen hatte" (223). En contra de esta interpretación, J. GNILKA, Petrus und Rom. Das Petrusbild in den ersten zwei Jahrhunderten, Herder, Freiburg 2002.

8. Es muy difícil determinar cuándo Pedro pudo llegar a Roma por primera vez. Según Eusebio, HE II 14,6, sucedió en tiempo del emperador Claudio. En la crónica, Eusebio indica que seguramente sería en el segundo año del emperador Claudio. Es imposible determinar de dónde obtuvo esta información. Cf. también Clemente Alejandrino, Strom VI 5,43. R. PESCH, Petrus 109s, cree que la llegada de Pedro a Roma tuvo que suceder, como muy pronto, en el 55. La ausencia de su nombre en la lista de saludos de la carta a los romanos se considera, normalmente, como un indicio de que Pedro no estaba en Roma cuando Pablo escribió la carta. 
comunidad cristiana de Roma entre los "romanos" asistentes a Pentecostés (Hech 2,10). Algunos de esos judíos habrían llevado la nueva fe a la capital del imperio 9 . En contra de esta suposición hay que decir, que la expresión oi

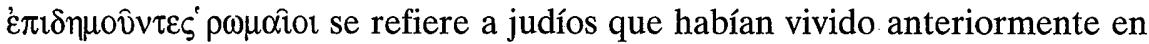
Roma, pero que habían cambiado su residencia a Jerusalén ${ }^{10}$. Por su parte, U. Wilckens considera que los primeros cristianos romanos eran miembros del grupo helenista en torno a Esteban de la sinagoga de los libertini (Hech 6,9), quienes después de su martirio fueron expulsados de Jerusalén y se trasladaron a la capital del imperio ${ }^{11}$. Algún estudioso ve plausible la hipótesis de que el cristianismo de corte petrino haya jugado un papel muy importante en los orígenes de la comunidad cristiana de Roma. Es de suponer que siendo Roma la capital del imperio, pronto llegaran a ella también misioneros cristianos portadores de otras tradiciones, y que todas ellas se fueron fusionando poco a poco $^{12}$.

Las fuentes son escasas. Es muy improbable que Pedro fuera el fundador de la(s) comunidad(es) de Roma. Pablo no se habría entrometido en una comunidad fundada por el mismo Pedro después del acuerdo de Jerusalén (Gal 2,7), ni por el deseo expreso de no construir sobre cimientos ajenos (Rom 15,20s). Por tanto, creo que no tiene sentido indagar por el fundador. Podemos simplemente afirmar que los primeros cristianos conocidos en la ciudad de Roma son Áquila y Priscila (Hech 18,1s), quienes ya eran cristianos antes de su expulsión de la capital del imperio. Del mismo modo, difícilmente podemos indicar cuándo llegó el cristianismo a Roma. Se supone que ya en tiempo de Tiberio $^{13}$ o de Calígula ${ }^{14}$ habían llegado las noticias de la

9. W. BeYschlaG, "Das geschichtliche Problem des Römerbriefs", in: ThStKr 40 (1867) $627 \mathrm{ss}$, cree que los peregrinos romanos se convirtieron en Jerusalén al jedeocristianismo. Por tanto, Pedro sería el origen -en Jerusalén, no en Roma- de la comunidad cristiana romana.

10. E.A. Judge - G.S.R. Thomas, "The Origin of the Church at Rome: A new Solution", in: RTR 25 (1966) 83, consideran que los "romanos" de Hech 2,10 "were so called because of their distinct civil status, not because they were Romans ethnically or had come from Rome".

11. U. WilCKENS, Röm I,38.

12. Santiago GUIJARRo, "La trayectoria y la geografía de la tradición petrina durante los tres primeros siglos cristianos", en: R. AGUIRRE MONASTERIo (ed.), Pedro en la Iglesia primitiva (Institución San Jerónimo 23), Verbo Divino, Estella 1991, 17-28. Es, pues, un hecho históricamente bastante probable, que explicaría la implantación en Roma desde muy temprano de un cristianismo más vinculado a sus raíces judías que el de Pablo.

13. Algunos estudiosos afirman que las primeras noticias de la nueva fe habrían llegado a Roma viviendo Jesús. Esta hipótesis se apoya en una vieja tradición, pero sin visos de historicidad: Ps.-Clementinas, Rec 1,7s.; Hom 1,7s.; cf. Tertuliano, apol. 5,2. La mayoría de los autores consideran esta información como una invención apologética.

14. Cf. S. Agustín, epist. 102,8, menciona que la "Ley de los judíos" llegó en tiempos de Calígula desde Siria a Roma. M. Hengel, Zur urchristlichen Geschichtsschreibung, Stuttgart 1979, 91 , indica que esta noticia se refiere a la secta cristiana. 
muerte y resurrección de Jesús de Nazaret a alguna comunidad judía de Roma, sin que se pueda precisar por medio de quién y cómo. Del edicto de Claudio, se concluye que, como muy tarde, en los años 48-49 existió en Roma un círculo activo de cristianos, cuya postura frente a la sinagoga era problemática. La falta de datos concretos impide una explicación más concreta de la aparición de las comunidades romanas así como una datación más precisa de la llegada del cristianismo a Roma. Se puede suponer que los primeros misioneros cristianos pisaron suelo romano a comienzos de los años $40^{15}$.

Problemático es también el origen de estos primeros misioneros. Dado que éstos habían llegado a la capital antes que Pablo comenzara su misión en Europa, hay que concluir, por tanto, que procedían del Oriente Próximo, donde Jerusalén era el centro del judeocristianismo y Antioquía del paganocristianismo. La decisión de optar por una de esas dos ciudades depende si consideramos a los primeros cristianos de Roma como paganocristianos ${ }^{16} \mathrm{o}$ judeocristianos. Los acontecimientos históricos del año 49 (Hech 18,1-2) dejan entrever, sin embargo, su origen judío. Dado que los altercados tuvieron lugar en una o más sinagogas, se puede afirmar que los misioneros cristianos eran judeocristianos. Solamente ellos tendrían acceso a las sinagogas. La expulsión de Priscila y Áquila, dos judeocristianos, confirma la presencia de este grupo en Roma. Aceptando que existía un contacto permanente entre el judaísmo de Palestina y de Roma (Hech 28), se puede suponer que también el cristianismo llegó a la capital del imperio desde Palestina ${ }^{17}$. No se debe excluir que este cristianismo de Roma sufriera influjos posteriores del cristianismo helenista de Asia Menor o de Grecia.

Los primeros cristianos de origen no judío en Roma procedían de grupos greco-hablantes que estaban en contacto con el judaísmo, es decir, procedían de los prosélitos o temerosos de Dios que frecuentaban la sinagoga. Éstos se convirtieron en el principal objetivo de los misioneros cristianos. Además, el cristianismo constituía para los "temerosos de Dios" una doctrina atrayente

15. Véase H. Lichtenberger, "Josephus und Paulus in Rom. Juden und Christen in Rom zur Zeit Neros”, en: KOCH, D.A. - LICHTENBERGER, H. (ed.), Begegnung zwischen Christentum und Judentum in Antike und Mittelalter. FS H. SCHRECKENBERG (SIJD 1), Göttingen 1993, 245.

16. W. SchmiTHALS, Römerbrief $67 \mathrm{~s}$., cree que los primeros cristianos eran pagano-cristianos procedentes de Antioquía, pues sólo así es comprensible el hecho de que Pablo considerara en Rom a la comunidad como pagano-cristiana. Excluye, sin embargo, una uniformidad del cristianismo romano, pues el pagano-cristianismo tampoco era uniforme.

17. Vgl. R.E. Brown - J.P. MeIER, Antioch and Rome. New Testament Cradles of Catholic Christianity, New York - Ramsey 1983, 126: "Roman Christianity came from Jerusalem in the 40s". El Ambrosiaster menciona en su comentario sobre la carta a los Romanos (PL $17.48=$ CSEL 81,1,5-6), que los romanos llegaron a la fe en un contexto judío (ritu licet Judaico). 
dado que les prometía la salvación sin necesidad de circuncisión. El cristianismo romano antes del Edicto de Claudio estaba compuesto de una mayoría de judeocristianos y de una minoría de pagano-cristianos (temerosos de $\left.\operatorname{Dios}^{18}\right)$. Posiblemente se reunían en algunas casas cristianas. Debido a los estrechos contactos del cristianismo con el judaísmo, es de suponer que la población cristiana se concentró, ante todo, donde vivían los judíos ${ }^{19}$. La rápida expansión del cristianismo en Roma se debió al sistema organizativo de las sinagogas: la multiplicidad de comunidades ${ }^{20}$, la organización interna democrática y la ausencia de una autoridad central judía facilitó a los misioneros cristianos la posibilidad de acceder a las sinagogas y ganar adeptos en ellas.

Con la intensificación de la misión en la diáspora después del acuerdo de Jerusalén, también aumentó la tensión entre la sinagoga y los nuevos misioneros. Estos últimos provocaron discusiones teológicas sobre la mesianidad de Jesús tan acaloradas que empeoraron las relaciones entre los nuevos cristianos y los tradicionales miembros de la comunidad sinagogal, lo que provocó una serie de enfrentamientos violentos ${ }^{21}$. Claudio expulsó de Italia a los provocadores judíos y cristianos mediante un edicto ${ }^{22}$. Los pagano-cristianos seguramente no se vieron afectados por el edicto de Claudio, dado que ellos, como simples simpatizantes de la sinagoga, no se habrían inmiscuido en las discusiones internas judías. De todos modos, el edicto de Claudio indica que a finales de los años 40 estallaron conflictos en Roma a causa de Cristo, que conllevaron la toma de medidas policiales. Dichos altercados pudieron surgir sólo si los judeocristianos que habían creído en Jesús, tenían cierta resonancia dentro de las sinagogas. La noticia de la expulsión se expandió rápidamente a otras sinagogas romanas. Los judíos vieron en el cristianismo una factor desestabilizador y un peligro para el judaísmo en Roma. Lo más probable es que reaccionaran prohibiendo la entrada de los cristianos en las sinagogas. Por eso, es de suponer que las relaciones entre judíos y cristianos en Roma

18. W. SchmithaLs, Römerbrief 87 , n. 243 , considera que las medidas imperiales son comprensibles sólo si estaban implicados los pagano-cristianos en los altercados.

19. P. LAMPE, Die stadtrömischen Christen in den ersten beiden Jahrhunderten. Untersuchungen zur Sozialgeschichte (WUNT II 18), 2. Aufl., Tübingen 1989, 30-52, analiza la distribución y la procedencia social de la población cristiana romana en los dos primeros siglos.

20. De las 13 sinagogas que hubo en Roma, tres o cuatro ya existían en el siglo I d.C. cf. H.J. Leon, Jews 149 s.

21. Véase W. WIEFEL, "Die jüdische Gemeinschaft im antiken Rom und die Anfänge des römischen Christentums. Bemerkungen zu Anlaß und Zweck des Römerbriefes", in: Jud. 26 (1970) 75 .

22. Cf. David Álvarez Cineira, Die Religionspolitik des Kaisers Claudius und die paulinische Mission (HBH 19), Herder, Freiburg 1999. 
fueron bastante tirantes después de la expulsión, si es que no se llegaron a romper ${ }^{23}$.

\section{Las comunidades cristianas romanas después del edicto de Claudio}

El edicto de Claudio tuvo consecuencias importantes para el cristianismo naciente. La composición del cristianismo romano después del edicto no es claro. Su uniformidad es bastante improbable ${ }^{24}$. Más razonable es pensar que las reacciones cristianas ante el edicto fueron diferentes según el grado de adhesión al cristianismo. Los judeocristianos que provocaron los altercados y que debieron abandonar la ciudad, serían acérrimos defensores de la mesianidad de Jesús y partidarios convencidos del cristianismo. Junto a ellos habría un grupo de judeo- y pagano-cristianos, conocido en las sinagogas como cristiano, pero que no participó en los altercados, por lo que pudo continuar viviendo en Roma. Su relación con el judaísmo, sin embargo, se vería interrumpida: se separarían o fueron expulsados de la sinagoga y se organizarían autónomamente. Éstos, que constituirían la mayoría del grupo cristiano en Roma, se reunirían en casas particulares para evitar represalias y problemas con los judíos. Otros judíos y temerosos de Dios, que no estaban convencidos totalmente de la mesianidad de Jesús, continuarían frecuentando asiduamente la sinagoga y solamente mantendrían un contacto esporádico con parientes o conocidos cristianos. La diferencia entre judíos y judeocristianos no era fácil de determinar, a no ser que el judeocristiano se diera a conocer como tal. Por tanto, es comprensible que entre los cristianos romanos existieran algunos judeocristianos que no quisieran romper totalmente con la forma de vida de la sinagoga, por lo que continuaron gozando de los privilegios judíos. Otro grupo de judíos y temerosos de Dios, que antes del edicto mantenían contactos esporádicos con el cristianismo, en vista de la amenazante situación política y de las presiones familiares romperían toda relación con el cristianismo.

23. P. LAMPE, Christen 9, considera la separación del cristianismo de la sinagoga como una consecuencia de la expulsión. Cf. también R. BRÄNDLE - E.W. STEGEMANN, "Entstehung" 9.

24. R.E. Brown - J.P. Meier, Antioch 92-127, y P.S. MineAR, Obedience 12-17, ven dentro de la iglesia romana algunos grupos que representan a las diversas tendencias dentro de la Gran Iglesia (desde los judaístas extremistas hasta los libertinistas). Estos grupos estaban en conflicto entre ellos. F.F. BRUCE, "The Romans Debate-Continued", in: Donfried, K.p. (ed.), The Romans Debate, Edinburgh 1991, 186, subraya la variedad y heterogeneidad de las comunidades cristianas romanas "in thought and practice between the firm Jewish retention of the ancestral customs and Gentile remoteness from these customs, with some Jewish Christians, indeed, found on the liberal side of the halfway mark between the two extremes and some Gentile Christians on the 'legalist' side". 
Por tanto, podemos deducir que los cristianos que permanecieron en Roma después del edicto de Claudio eran judeocristianos ${ }^{25}$ y pagano-cristianos, los cuales no se separaron unos de otros, sino que continuaron reuniéndose en casas privadas $^{26}$. A partir de entonces, la labor misionera de los cristianos en las sinagogas romanas fue imposible. De este modo, el campo de misión se redujo fundamentalmente a ambientes familiares de los paganocristianos. Éstos llegarían a ser paulatinamente mayoría dentro de la comunidad romana. La organización de los cristianos que permanecieron en Roma después del edicto hasta la muerte de Claudio no es fácil de determinar porque no tenemos información al respecto ${ }^{27}$.

Muerto Claudio (54 d.C), el edicto de expulsión dejó de tener vigor. Los judíos y judeocristianos expulsados pudieron regresar a Roma. Algunos autores consideran que los judeocristianos que regresaron a Roma $^{28}$, debido a la distinta interpretación de la creencia cristiana, constituirían comunidades separadas de los cristianos que habían permanecido allí con la consiguiente desestabilización de las comunidades existentes. Sin embargo, esta hipótesis es improbable dado que los afectados -aunque eran judeocristianos- compartían las mismas ideas teológicas de los paganocristianos romanos. Éste era el caso de la comunidad formada en torno a Áquila y Priscila, así como también de las comunidades domésticas mencionadas en Rom 16.

25. Estos judeocristianos desarrollaron posiblemente su propia posición teológica como consecuencia de la separación de la sinagoga. Su designación como "Judeocristianos" no significa que defendieran la misma posición teológica que los judeocristianos de Palestina. R.E. BROWN - J.P. MEIER, Antioch 126, consideran el cristianismo romano como "a moderate Jewish/Gentile Christianity favorable to Peter".

26. Los problemas reflejados en Rom 14-15 indican la existencia de contactos entre judeoy pagano-cristianos dentro de las comunidades domésticas:

27. J.S. JEFFERS, Conflict at Rome. Social Order and Hierarchy in Early Christianity, Minneapolis 1991, 40, considera que los cristianos tomaron la estructura sinagogal como modelo para la formación de las comunidades domésticas judeocristianas, pero con la característica de que se convirtieron en un grupo clandestino, dado que los cristianos ya no estaban bajo la protección de los privilegios judíos. Se constituyeron como asociaciones libres sin una directa relación con la sinagoga. Para los pagano-cristianos, J.S. Jeffers propone la tesis de que se habrían organizado como un colegio funerario (collegia funeraticia). Como tales asociaciones, se podían reunir en casa de algún miembro o patrón sin levantar las sospechas de los romanos. Sin embargo, no existen testimonios para esta suposición.

28. Estos autores creen que todos los judeocristianos tuvieron que abandonar la ciudad. $\mathrm{H}$. Appel, Einleitung in das Neue Testament, Leipzig 1922, 45, presupone el regreso a Roma de la mayoría de los expulsados, tanto judíos como judeocristianos, por lo que la comunidad cristiana dejaría de ser pagano-cristiana. Para A.J.M. WedDERBURN, The Reasons for Romans, Edinburgh 1988, 64s., la principal tarea de los pagano-cristianos después del Edicto fue la integración de los judeocristianos expulsados en las comunidades domésticas. 
Los judíos expulsados y que regresaron a Roma, provocaron dificultades al cristianismo (Rom 12,14.17-21). Estos judíos consideraban a los judeocristianos como responsables de la expulsión. Las tensiones del año 49 volvieron a estar otra vez en primer plano. Lógicamente, los judíos intentarían aprovechar las buenas relaciones con la corte imperial (Josefo, AJ XX 195; Vit. 16) para vengarse de los cristianos: El peligro de una nueva expulsión, en caso de que los judíos (cristianos) volvieran otra vez a alterar la paz en Roma, se cernía sobre las comunidades judías y cristianas de la capital. Pablo insta a los cristianos a evitar la venganza y las represalias (Rom 12,17) contra los perseguidores judíos, pues ello provocaría un recrudecimiento de la violencia y un empeoramiento de la situación entre judíos y cristianos. Nuevos altercados en Roma habrían propiciado medidas más duras que las tomadas por Claudio. Una confrontación con los judíos y la alteración de la pax romana habría puesto en peligro la misión del Apóstol en Jerusalén, así como su deseo de visitar Roma y la supervivencia del cristianismo en la capital. Por eso Pablo puso tanto empeño en evitar nuevos choques en Roma.

\section{El cristianismo de Roma según la carta a los romanos}

Cuando escribió la carta, Pablo no había visitado la comunidad, pero según el cap.16 conocía a algunos de sus miembros, los cuales habrían trabajado con él en Oriente y le habrían informado de la situación de los cristianos en Roma. Esto se ve p.e. en Rom 14-1529. Un análisis de los pasajes Rom $1,7.8 ; 6,17 \mathrm{~s}$; 15,$14 ; 16,19$ lleva a concluir que el apóstol conocía el grado de creencia de los cristianos romanos. Por otra parte, la carta presupone que la misión paulina no era totalmente desconocida en la metrópoli30. Según el pasaje Rom 3,8 hay indicios para pensar que las comunidades cristianas romanas habían recibido juicios negativos sobre Pablo.

La carta a los romanos no menciona la "Ekklesia" de Roma o la iglesia de los romanos ${ }^{31}$. Tal ausencia hace muy probable que existieran diversas

29. N. SCHNEIDER, Schwachen 8-49, concluye en su estudio que Pablo tenía presente a la hora de componer Rom $14 \mathrm{~s}$ un conflicto concreto dentro de la comunidad cristiana romana. Según P. LAMPE, Christen 56, dicho conflicto era entre los "débiles" y los "fuertes". Otros exégetas consideran Rom 14-15 como una parénesis general, cf. R.J. KARRIS, "Romans 14:1-15:13 and the Occassion of Romans", in: DoNFRIED, K.P. (ed.), Debate 84; E. KÄSEMANN, Röm 348ss.

30. R.E. Brown - J.P. MEIER, Antioch 113.

31. L.A. JERvIS, The Purpose of Romans. A Comparative Letter Structure Investigation (JSNT.S 55), Sheffield 1989, 82.162s., defiende la idea de que Pablo evitó la mención de Ekklesia para poder dirigirse a todos los cristianos individualmente en vez de a una o a más comunidades. 
comunidades (cfr. Rom 16). A pesar de que la posición de Watson de "dos comunidades romanas" en el sentido de dos posiciones teológicas, pudiera ser correcta, parece sin embargo que la presuposición de al menos tres (Klauck ${ }^{32}$ ) o incluso ocho comunidades (Lampe ${ }^{33}$ ) corresponda más a la realidad del cristianismo romano. Cuando Pablo compone la carta a los Romanos, las iglesias locales estaban formadas principalmente de paganocristianos. De algunos pasajes de la carta (Rom 1,5.13-15; 11,13.17s.24.28.30s.; 15,15s.18; 9,3ss.) concluye W. Schmithals 34 : "Está fuera de toda duda que los cristianos romanos a los que Pablo escribe, según la opinión de Pablo, son paganocristianos". Pablo se dirige expresamente en la carta a los ع́ $\theta v \varepsilon \sigma \iota v$. Pasajes como Rom 11,24s., unido a Rom 11,30.28.17s., muestra que $\varepsilon$ $\theta v \eta$ se usa para indicar el grupo étnico de los cristianos romanos y designa su procedencia del paganismo. Sin embargo, el contenido de la carta presupone también destinatarios judeocristianos $(9,24)$, así como el tema de los fuertes y los débiles en Rom $15 \mathrm{~s}$., que gira en torno a la cuestión de la observancia judía de la ley35. Pablo da por supuesto que los lectores tienen un buen conocimiento del AT (Rom 7,1.4; 2,17; 4,1). Habla en Rom 4,1 de Abraham, "nuestro" predecesor según la carne. Por tanto, parece que la carta a los romanos contiene una contradicción interna: mientras que el tratamiento directo del apóstol se refiere a paganocristianos, la argumentación paulina presupone un público judeocristiano. Se han presentado varios intentos de solución: Estos paganocristianos eran los simpatizantes o temerosos de Dios, por tanto conocedores del AT. O tal vez habría que suponer que la carta se dirige tanto a judeocristianos como a paganocristianos con el objetivo de reconciliar a los dos grupos (los fuertes y los débiles) ${ }^{36}$, tal y como muchos investigadores concluyen de Rom $14 \mathrm{~s}^{37}$. N. Schneider considera a los "débiles" como una minoría judeocristiana dis-

32. H.-J. KLAUCK, Hausgemeinde 26ss.

33. P. LAMPE, "The Roman Christians of Romans 16", in: DonfrIED, K.P. (ed.), The Romans Debate, Edinburgh 1991, 230, piensa que habría ocho comunidades: "The number grew to at least eight when Paul himself started to assemble Christians in his Roman rented lodging (Acts 28: 30-31)".

34. W. Schmithals, Römerbrief 11 . Sobre la problemática de la composición de la comunidad véanse las pp. 24-63.

35. Característico para los débiles en Rom 14 es la observancia de las prescripciones alimenticias (Rom 14,2.15.20s.), así como de algunos días concretos (Rom 14,5), que podrían ser el sábado y las fiestas judías.

36. F. WATSON, "Congregations" 206, presupone para Roma dos comunidades separadas que estaban en "mutual hostility and suspicion over the question of the law".

37. El porcentaje exacto de los dos grupos no es posible darlo, pero P. Lampe presupone que el $15 \%$ serían judeocristianos y el resto paganocristianos, cfr. P. LAMPE, "Christians" 225; Christen 57. 
puesta a un compromiso ${ }^{38}$, que sólo exigían para ellos unas mínimas exigencias legales. Esto no significa que todos los judeocristianos fueran "débiles en la fe". Los "fuertes" son identificados como pagano-cristianos ${ }^{39}$ liberales. Varios exégetas, U. Wilckens ${ }^{40}$, R.E. Brown, D. Zeller y G. Strecker, sin embargo, evitan hablar de tal antagonismo étnico en Roma. Presuponen otros problemas: diversidad de costumbres, éticas y mentalidades.

Otro tema son los agitadores de Rom 16,17-20, quienes presumiblemente intentaran una re-evangelización judeocristiana ${ }^{41}$. Pero no se puede hablar de una misión directa contra Pablo, dado que todavía no había predicado en Roma, sino más bien de una incipiente misión ${ }^{42}$ contra la evangelización paulina de la comunidad romana realizada por sus colaboradores.

Los judeocristianos constituían una minoría dentro de la comunidad cristiana. Los que eran conocidos como tales, serían mal vistos por los judíos y considerados como traidores de la fe. Por eso estaban más o menos excluidos de las sinagogas romanas.

\section{Los hermanos según Hechos de los Apóstoles}

Junto a la información de la carta a los romanos, Lucas menciona en

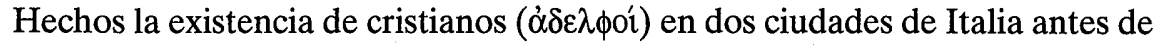
la llegada de Pablo a la capital del imperio: en Pozzuoli (Hech 28,13s) e indi-

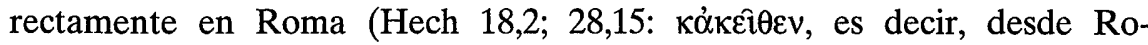
ma). Sin embargo, la presentación de la llegada y residencia de Pablo en estas ciudades es históricamente muy discutible y controvertida. En el puerto (Pozzuoli) se encuentra el apóstol con los cristianos de la ciudad y acepta la invitación de quedarse siete días con ellos, como si Pablo fuera un hombre libre $^{43}$. En el versículo 15, Lucas menciona que la comunidad cristiana de

38. N. SCHNEIDER, Die "Schwachen" in der christlichen Gemeinde Roms. Eine historisch-exegetische Untersuchung zu Röm 14,1-15,13, Diss. Wuppertal 1989; 123.

39. Para W. Schmithals, Römerbrief 103ss., tanto los "fuertes" como los "débiles" son paganocristianos.

40. U. WilcKens, Röm Bd. 1,40.

41. Algunos estudiosos consideran que Rom $16,17 \mathrm{~s}$ se refiere a los judaístas como enemigos paulinos: A. Suhl, Paulus 282; U. Wilckens, Röm Bd. 3,145; D. Zeller, Röm 249.

42. M. KeTtunen, Der Abfassungszweck des Römerbriefes (AASF.DHL 17), Helsinki 1979, $70 \mathrm{~s}$.

43. Es imposible pensar que el centurión estuviera dispuesto a esperar una semana a Pablo, cuando ya estaba tan cerca de su destino. E. HAENCHEN, Apg 642, ofrece una explicación convincente: "Lukas hat... V. 14a eingeschoben, damit während dieser. Woche die Ankunft des Paulus den römischen Christen gemeldet werden konnte". Contrario se muestra B. Rapske, Book 273-276. 
Roma envió dos delegaciones ${ }^{44}$ a su encuentro hasta el Foro Apio (a $65 \mathrm{~km}$ de Roma) y Tres Tabernas (48 km). Este recibimiento, que se podría comparar con una recepción de un alto diplomático ${ }^{45}$, tiene todos los visos de ser redaccional. Ésta es la única mención de los cristianos de Roma en la narración lucana. Desaparecen de la escena para que Pablo pueda aparecer como el primer misionero en Roma.

Otra tradición que Lucas usa, contiene algunas indicaciones sobre el encarcelamiento de Pablo en Roma (Hech 28,16b.30). Lucas coloca dos discursos de Pablo ante las autoridades de los judíos ${ }^{46}$. Estos discursos y el encuentro con los judíos son considerados entre los exégetas como una creación lucana ${ }^{47}$. Con el marco redaccional, Lucas quiere dejar traslucir que la predicación del cristianismo en la metrópoli había sido reconocida por el estado: un funcionario estatal (un soldado ${ }^{48}$, cf. Hech 28,16.30) había estado presente desde el inicio hasta el final de la misión del apóstol en Roma. Pablo, por tanto, no constituye un peligro para el imperio. El redactor presupone que los judíos de Roma no conocían todavía el mensaje cristiano, sin embargo querían informarse. Históricamente es muy improbable que los dirigentes

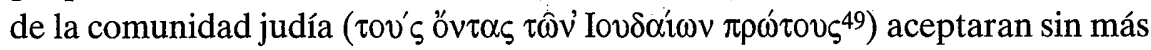

44. Hay dos posibles motivos para el envío de dos delegaciones distintas: a) La comunidad romana estaba divida y las dos delegaciones representaban a los dos grupos existentes en la comunidad, es decir, los "fuertes" y los "débiles". b) Según C.K. BARRETT, "End" 546, un grupo se componía de gente joven y el otro estaba formado por "the more sedentary members of the Roman church".

45. C.K. BARRETT, "The End of Acts", in: Lichtenberger, H. (ed.), Geschichte - Tradition Reflexion. Bd. 3: Frühes Christentum, Tübingen 1996, 546, designa la escena como una "triumphal procession".

46. Sobre la estructura narrativa de estos versículos cf. H.J. HAUSER, Strukturen der Abschlusserzählung der Apostelgeschichte (Apg 28,16-31) (AnBib 86), Roma 1979; J. ZMIJEWSKI, Apg 880-882, ve en la narración de las tractativas entre Pablo y los judíos (17a.17b.19.20a.21. 22a.23a) elementos de la tradición.

47. G. LüDEMANN, Das frühe Christentum nach den Traditionen der Apostelgeschichte. Ein Kommentar, Göttingen 1987, 273s., considera Hech 28,17-28 como "in toto lukanisch", tanto a nivel de contenido como lingüístico. Cf. J. MurPhy-O’Connor, Paul. A Critical Life, Oxford 1996, 354. 48. La custodia custodia militaris se componía de al menos dos soldados romanos. Sobre la prisión de Pablo en Roma véase el amplio estudio de B. RAPSKE, Book 227-242, quien parte sin embargo de la historicidad de los acontecimientos narrados en Hechos. Según este autor, Pablo fue custodiado por "a regular soldier and a solitary one" (p. 181); cf. M.-E. RosENBLATT, Paul the Accused: His Portrait in the Acts of the Apostles (Zacchaeus Studies: NT), Collegeville, Minnesota 1995, cap. 4. Sobre las distintas formas de custodia cf. F.H. HitzIG, "Custodia", in: PRE IV 2 (1901) 1896-1899; B. RAPSKE, Book 243-281.369-392; cf. R.J. CASSIDY, Paul in Chains. Roman Imprisionment and the letters of St. Paul, New York, Crossroad 2001.

49. No es claro quiénes eran estos dirigentes judíos. Según H.W. TAJRA, The Trial of Paul (WUNT II 35), Tübingen 1989, 184, serían "Presbyters, Archontes, Scribes and other leading men of the synagogues...". 
la invitación de un desconocido y presunto malhechor. Ello les habría hecho sospechosos ante las autoridades romanas. Del mismo modo es incomprensible la respuesta de los judíos: "No hemos recibido de Judea ninguna carta que nos hable de ti, ni ninguno de los hermanos llegados aquí nos ha referido o hablado nada malo de ti" (Hech 28,21). Los judíos parecen desconocer el grupo de los cristianos, lo cual es imposible según la información de Hech 18,2 y Rom 12. No podían haber olvidado tan pronto el edicto de Claudio, pues estaba reciente en el tiempo. Asimismo, es incomprensible que si Pablo fue acusado en Jerusalén y Cesarea por el Sanedrín, éste no hubiera buscado la ayuda de los judíos romanos para que intentaran influir en la corte imperial. Algún autor intenta solucionar esta dificultad diciendo que el informe judío sobre Pablo habría sido enviado a Roma, pero que en ese momento todavía no había llegado a la capital por las dificultades del viaje durante el invierno ${ }^{50}$. La discusión de Pablo con los judíos es una construcción lucana, como indica Hech 28,28. ¿Por qué debía anunciar Pablo a los paganos la gracia de Dios, si un grupo de judíos se había convencido mediante sus palabras? Difícilmente podría esperar el apóstol que se hubieran convertido todos los judíos después de un solo día de actividad misionera. Todo ello nos indica que la narración de la misión paulina en la capital está estructurada según un esquema de pensamiento típicamente lucano $^{51}$ y no sigue históricamente la sucesión de los acontecimientos.

Se presupone que Pablo permaneció en cárcel preventiva en Roma (custodia carceris o custodia libera et aperta et in usum hominis instituta ${ }^{52}$ ) hasta la reapertura del proceso y del enjuiciamiento. Aunque Lucas sabía bien lo que había sucedido a Pablo, no informa nada de su proceso ${ }^{53}$. Tampoco se menciona para nada la muerte de Pablo. Posiblemente el autor silencia la condena del apóstol por motivos apologéticos (apologia pro imperio para su igle$\mathrm{sia}^{54}$ ), dado que él abogaba por una buena relación de la comunidad cristiana

50. F.F. BRUCE, Acts 539.

51. B. PRETE, "Arrivo" 151.

52. Hech 28,16: Pablo vive junto con el soldado que le custodia. Una versión occidental

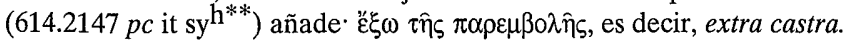

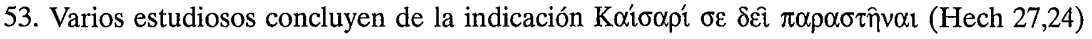
que Lucas sabía que Pablo había sido presentado ante el emperador. A.N. SHERwiN-White, Society 108-112, investiga el sistema judicial de Nerón y llega a la conclusión de que este emperador rara vez se dedicaba a las cuestiones judiciales, por lo que es de suponer que el caso de Pablo no fue tratado por el emperador, sino por un representante.

54. P.W. Walaskay, "And so we came to Rome". The Political Perspective of St. Luke (MSSNTS 49), Cambridge 1983, 64. G. GuTTENBERGER, "Ist der Tod der Apostel der Rede nicht wert? Vorstellungen von Tod und Sterben in den lukanische Acta", en: F.W. HoRN (ed.), Das Ende des Paulus. Historische, theologische und literaturgeschichtliche Aspekte (BZAW 106), De 
con el estado romano. H.W. Tajra ${ }^{55}$ resume con estas palabras el objetivo político y apologético de la obra lucana:

"Luke... stressed to his readers that Rome did not view nascent Christianity as an illicit or subversive movement, intrinsically hostile to the state and its ruler and actively bent on subverting or overthrowing the Principate. He constantly represents the Christians as loyal and apolitical subjects of the Emperor and their communities as politically unthreatening (apologia pro ecclesia). Luke... directs his reader's attention to the Roman authorities' benevolence towards the Church and to the political stability and peace which the Principate provided and which allowed the Christian mission to progress with such rapid strides (apologia pro imperio)".

Sobre el final de la vida de Pablo solo se puede especular. El texto de Hechos de los Apóstoles permanece abierto ${ }^{56} \mathrm{y}$, por tanto, no se puede afirmar con rotundidad que Pablo fuera condenado a muerte inmediatamente después de su presidio ${ }^{57}$. Por ello, se han presentado diversas hipótesis ${ }^{58}$.

Según algunas tradiciones cristianas (1 Clem 5,5-7; 1Tim 6,13; MPol 1,1; 19.21s. $\left.{ }^{59}\right)$ se presupone que Pablo murió en Roma. 1 Clem 5,4-7 (95-97 d.C) escribe:

Gruyter, Berlin 2001, 304s., considera el final abierto de Hechos como el planteamiento de una disyuntiva a las autoridades romanas del tiempo de Lucas de convertirse en instrumento de Dios para la salvación o, por el contrario, en enemigos de Dios, como había sucedido al Sanedrín de Jerusalén o a Herodes Agripa I.

55. H.W. TAJra, The Martyrdom of St. Paul. Historical and Judicial Context, Traditions and Legends (WUNT II 67), Tübingen 1994, 38. Varias leyendas sobre el martirio del apóstol pre-

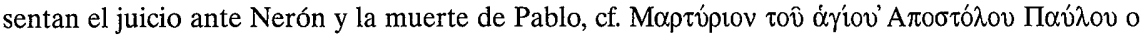
Passio Pauli Fragmentum.

56. El final abierto de Hechos es considerado por algunos exégetas como una figura retórica, típica en la literatura greco-romana. D. MARGUERAT, "Énigme" 1-21, denomina esta figura como "la suspension narrative" (p. 1). J. DuPONT, "Conclusion" 457-511, esp. 483-511, ofrece un estudio clásico sobre el final de Hechos.

57. A.N. SHERwin-White, Society 119, C.K. BARRETt, "End" 546, y J. MurPhy-O'Connor, Paul 355, consideran la posibilidad de que Pablo fuera puesto en libertad gracias a la clementia imperial.

58. Véase R. Pesch, Apg Bd. 2,311s. C.K. BARRETT, "End" 548, considera posible la liberación del apóstol. De los pasajes 2 Tim 4,16 y 1 Clem 5,5 concluye este autor (p. 550), que Pablo fue abandonado por los cristianos romanos: "Luke did not see fit to tell the story of it. Paul's relation with the Roman church may have been stormy and in the end non-existent". Cf. también J. MuRPHY-O'CONNOR, Paul 360s.369s.

59. Cf. Ignacio, Eph 12; Policarpo, Phil 9. Otros testimonios de los Padres en H.W. TAJRA, The Martyrdom 172-194.

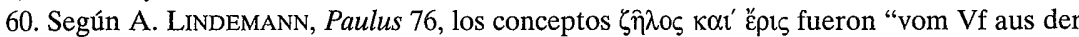
aktuellen Absicht heraus gewählt worden". J. RoLofF, Apg 372, entiende estas intrigas y rivali- 
"Pablo, que, también a consecuencia de la envidia y la discordia ${ }^{60}$, puso de manifiesto el premio que le está reservado a la constancia. Cargado siete veces de cadenas, exiliado, lapidado y constituido en heraldo en Oriente y Occidente, recibió la esplendorosa fama a que su fe le hizo acreedor. Tras haber enseñado la justicia al mundo entero y haber llegado a los extremos de Occidente ${ }^{61}$, dio

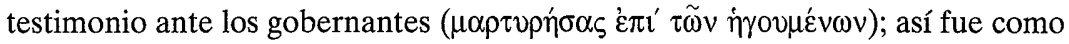
abandonó el mundo y marchó a la morada de santidad, modelo ilustre de constancia"62.

Se ha visto en este texto una alusión al martiro de Pablo. Sin embargo, esa hipótesis es discutible como posteriormente evidenciaremos al tratar el martirio de Pedro ${ }^{63}$. 2 Tim se presenta como una carta desde la prisión de Roma, en la que se presupone el aislamiento de Pablo y su martirio ( 2 Tim 1,15; 4,6-8): "En mi primera defensa, nadie salió a mi favor". No obstante, no es claro si se refiere al proceso en Jerusalén-Cesarea o al primer interrogatorio en Roma ${ }^{64}$. Estos son los principales testimonios pertenecientes a finales del siglo I. En los siguientes decenios no existe un desarrollo constatable de la tradición. Ignacio, Rom 4,3 parece conocer la tradición del martirio de Pablo, pero no menciona ningún detalle. Del mismo modo, Policarpo, Phil 9 insinúa la tradición del martirio. Obtenemos nueva información a partir de la segunda mitad del siglo II con los Hechos de Pablo65, los cuales narran claramente su martirio.

dades como conflictos entre los miembros de las comunidades cristianas. Para L. WeHr, Petrus 300 , muchas de las indicaciones de 1 Clem están acomodadas a la finalidad de la argumentación y no puede "für die historische Rückfrage fruchtbar gemacht werden. So darf man auch nicht

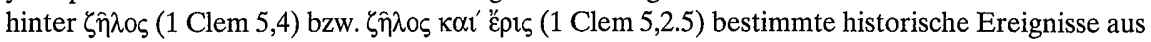
dem Leben der Apostel suchen".

61. Se cuestiona si 1Clem se refiere al viaje de Pablo a España (Rom 15,24.28; A. Petr. C. Sim. 1; Canon Muratori). El "extremo Occidente" podría referirse a Roma cf. A. Lindemann, Paulus 78s. No es seguro, según L. WEHr, Petrus 300, que se pueda concluir de las indicaciones de 1 Clem que los dos apóstoles murieron en Roma.

62. A. Lindemann, Die Clemensbriefe 39: No se puede afirmar con seguridad si esos "gobernantes" se refieren a las autoridades ciudadanas, las cuales conocemos de la presentación lucana de Hechos, o si el autor de 1 Clem entiende con ello el tribunal imperial. "Das Bild ist ja stilisiert, wenn auch nicht ohne Anhalt an der überlieferten Biographie des Paulus. Danach (ov $\omega \varsigma$ ) schied Paulus aus der Welt; von einem gewaltsamen Tod ist nichts gesagt (s. aber 5,2; es ist von daher fraglich, ob der Vf wirklich aus politischen Gründen auf das Martyrium nicht eingeht". (39)

63. Muy crítico se muestra A. Lindemann, Paulus 79: "Hinter 1 Clem 5,5-7 steht keinerlei authentische Detailkenntnis der Biographie des Paulus... Kenntnis der paulinischen Briefe ist an dieser Stelle ebensowenig sichtbar wie Kenntnis der (Traditionen der) Apg".

64. R. Pesch, Apg Bd. 2,313.

65. La primera mención sobre los Hechos de Pablo se encuentra en Tertuliano (200 d.C.) quien los considera como una falsificación (de bapt 17). Por el contrario, Hipólito, Dan III 29,4 y Orígenes, princ I 2,3; comm in Joh XX 12 conocen y utilizan dicha obra.

66. Véase la crítica en Harry W. TAJRA, The Martyrdom 101. 
La tradición de que los dos apóstoles, Pedro y Pablo, sufrieron prisión (en el Foro Romano, Mamertinum ${ }^{66}$ ) y murieron en Roma como mártires se ha puesto desde hace tiempo en duda y ha sido muy discutida. L. Wehr resume los resultados de la historia de la investigación sobre este tema de la siguiente forma: "Heute dürfte die Frage insofern geklärt sein, als sich zwar nicht zwingend nachweisen läßt, daß beide in Rom starben, daß aber die Wahrscheinlichkeit dafür spricht"67.

Hay autores que se apoyan en un pasaje de Eusebio para afirmar que Pablo estuvo encarcelado dos veces en Roma68: La primera se refiere a la apelación "appello ad Caesarem" y habría concluido con que los cargos presentados contra Pablo no fueron defendidos por ningún demandante del sanedrín, dado que éstos no comparecieron ante el tribunal ${ }^{69}$ (cf. Hech 28,21); después de su puesta en libertad, Pablo continuaría misionando en occidente (España). La segunda encarcelación en Roma se debería a la acusación crimen laesae maiestatis. Contra la historicidad de esta indicación se aduce que Eusebio habría sacado la conclusión erróneamente de Hech, Filip 2,24 y de 1 Clem.

El canon de Muratori 35-39 (250 d.C) menciona el viaje de Pablo a España (usque ad ultimum terrae), pero no su muerte. Eusebio, HE II 22,1-8; 25,5s.; III 1,3 narra el final de la vida de Pablo, pero no dispone de más información que nosotros. Esto indicaría que el silencio de las fuentes no se debe a una casualidad de la tradición, sino que corresponde a la situación real de las fuentes: o no existía ninguna información sobre el final de Pablo o los tradentes cristianos tenían sus motivos para no transmitir dicha información.

Oscar Cullman formuló una hipótesis donde propone identificar a los acusadores de Pablo como miembros de la comunidad cristiana romana ${ }^{70}$. Este autor subraya el silencio sobre la muerte de los apóstoles, Pedro y Pablo, tanto en Lucas (Hech 28) y en Clemente de Roma (EpCor 5), interrogándose por los motivos de dicho silencio. Tras examinar las evidencias lingüísticas

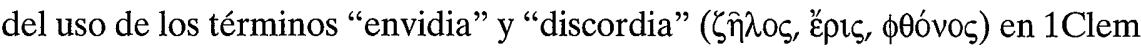

67. L. WeHr, Petrus 357. Vgl. P. LAMPE, Christen 83.

68. Cf. F. PFISTER, "Die zweimalige römische Gefangenschaft und die spanische Reise des Apostels Paulus und der Schluß der Apostelgeschichte", in: ZNW 14 (1913) 216-221; H.W. Tajra, Martyrdom 73-117; J. Murphy-O'CONNOR, Paul 359-363.

69. Por el contrario, F.F. BRUCE, Acts 541s., afirma que la no comparecencia del demandante ante el tribunal "would not inevitably lead to the discharge of the defendant". Ampliamente sobre el tema A.N. SHERwIN-WHITE, Society 112-116.

70. Esta teoría fue presentada en un artículo "Les causes de la mort de Pierre et de Paul d'après le témoignage de Clément Romain", en: RHPR 10 (1930) y en su libro Petrus. Jünger Apostel - Märtyrer, 2. Aufl., Zwingli Verlag, Zürich - Stuttgart 1960, 87ss. 
y las evidencias literarias, Cullmann llega a esta conclusión: Pedro y Pablo murieron víctimas de los mismos cristianos. Con ello no pretende decir que fueron martirizados por sus propios correligionarios, sino que las autoridades romanas intervinieron contra ellos por la actitud o denuncia de algunos cristianos romanos, del mismo modo que Moisés tuvo que huir del rey de Egipto debido a la envidia de un "compatriota". La envidia de la que habla Clemente no se explica con más detalle y no podemos decir con exactitud en qué consistió. Pero en cualquier caso, parece ser que fue la envidia de los cristianos y no la de las autoridades romanas la que causó la muerte de los apóstoles. Las autoridades romanas no tenían motivos en ese tiempo para tener envidia de un grupo insignificante. Cullmann cree que hubo en Roma una disputa tan violenta entre cristianos que atrajo la atención de las autoridades romanas. Éstas intervinieron y mataron a los dos líderes. Así explicaría el silencio deliberado de Lucas y Clemente para evitar recordar este acontecimiento trágico y penoso de la historia de la iglesia romana.

Este silencio sobre la muerte de los dos apóstoles originó que los escritores cristianos posteriores carecieran de información. Así se explica, concluye Cullmann, el hecho de que tengamos tan pocos testimonios del martirio en la literatura cristiana: sin lugar a dudas, se intentó silenciar las penosas circunstancias en que había sucedido la muerte de Pablo. La actitud de los cristianos, que causaron la muerte de otros cristianos, no era muy edificante para el resto de la comunidad. Por eso el final abrupto de los Hechos. La hipótesis de Cullmann, tan atractiva a primera vista, tiene sus puntos discutibles como han demostrados varios críticos ${ }^{71}$.

Pronto se creó la leyenda sobre la decapitación del apóstol (Martyrium tou Hagiou Apostolou Paulou y la Passio Pauli Fragmentum), así como la tradición apócrifa (Acta Pauli), que constituyó la clave fundamental para el desarrollo posterior de la tradición paulina ${ }^{72}$ : apócrifa, patrística e iconográfica. Los acontecimientos históricos de la muerte de Pablo fueron eclipsados y oscurecidos en este proceso dinámico de imaginación narrativa. Destaca el hecho de que Pedro está totalmente desconectado del ministerio de Pablo en Roma. Las fuentes máws antiguas parecen desconocer el ministerio común de Pedro y Pablo y su martirio conjunto en Roma.

71. Crítica en H.W. TAJRA, Martyrdom 81-84; Otto KARrer, Peter and the Church. An Examination of Cullmann's Thesis (QD 8), 3. Aufl., Herder and Herder - Burns \& Aother Limited, New York - London 1970.

72. Para la literatura cristiana apócrifa posterior (Pseudo-Marcellus, Acta Petri et Pauli [la cual no relaciona a los apóstoles en Roma], Passio Apostolorum Petri et Pauli, Historiae Apostolicae de Pseudo-Abdías) véase H.W. TAJRA, Martyrdom 143-165. 
Si tomamos en consideración las noticias contenidas en Hech 21,27-28,31, tenemos que afirmar que la presentación lucana tiene poco de histórico. En otro trabajo ${ }^{73}$ ya he analizado y criticado la presentación apologética que hace Lucas de Pablo, cuestionando la supuesta ciudadanía romana mencionada únicamente en Hechos: su ciudadanía romana no concuerda con la información transmitida por el propio Pablo sobre su vida, sino que sería más bien una invención literaria lucana por motivos apologéticos. Históricamente podemos afirmar y aceptar un viaje de Pablo desde Jerusalén o Cesarea hasta Roma. Sin embargo, las circunstancias del viaje nos son desconocidas, pues el traslado que hace Lucas es históricamente imposible. Considero más probable que Pablo llegó a Roma como hombre libre. Su predicación en Roma y el encuentro con los dirigentes judíos son, según la narración lucana, poco creíbles. Los judíos romanos afirman que ellos no han recibido de Judea ninguna carta que hable de Pablo y nadie de los hermanos judíos llegados a Roma les habían informado o referido algo malo sobre el apóstol (Hech 28,21). Los contactos constantes entre los judíos de Roma y Jerusalén hace improbable ese desconocimiento de los judíos romanos, porque el apóstol ya había tenido diversos altercados con los judíos en la diáspora. Según el texto de Rom 15,32, es de suponer que Pablo entró en contacto con los cristianos de Roma. Sólo podemos imaginar que el apóstol tendría alguna dificultad con las autoridades civiles, por lo que fue apresado y condenado. Pero nos es desconocido el motivo de la condena: posiblemente surgieron conflictos y envidias entre los judeocristianos y el apóstol o entre los judíos y Pablo. Todas estas cuestiones sobre el final de su vida no pueden ser respondidas por la escasez de información.

Vista la relación de Pablo con Roma, analizaremos ahora la vinculación que tuvo Pedro con la comunidad cristiana de la metrópoli imperial.

\section{Pedro y la comunidad romana}

Si Pedro no fue el fundador de la comunidad romana, ¿por qué llegó a ser la figura central? Tuvo que tener una relación especial con Roma, de otra forma no se explica tal relevancia. Por eso tenemos que dilucidar si efectivamente Pedro vivió en Roma los últimos años de su vida y murió allí. Este aspecto de la vida de Pedro ha estado siempre en estrecha conexión con el tema controvertido de la primacía petrina.

73. D. Álvarez Cineira, "Pablo, ¿un ciudadano romano?", en: EstAg 33 (1998) 455-486. 
El NT no aporta indicación alguna sobre la estancia de Pedro en la capital del imperio. Pedro desaparece del relato de Hechos después del concilio de Jerusalén. El silencio del NT, en particular la epístola a los Romanos y Hechos, no es concluyente para afirmar o negar la tradición de que Pedro vivió en Roma, excepto para el presupuesto que si estuvo alguna vez allí, no estaba en esa ciudad cuando Pablo escribió su carta a los Romanos. Tampoco se puede argumentar nada desde Gal 2. En 1 Pet 5,13, escrita a finales del siglo I, encontramos el primer testimonio fiable de la tradición de que Pedro visitó Roma. Este postulado también pudiera ser apoyado por el testimonio de Ignacio, Rom 4,3 (c. 110 d.C.), y posiblemente por un fragmento de Papías (150 d.C) conservado en Eusebio. Otras indicaciones aparecen en $1 \mathrm{Clem} 5$ (96 d.C.) y en Dionisio de Corinto. En torno al año 170, en la carta de Dionisio de Corinto a Soterio, obispo de Roma, Pedro y Pablo aparecen asociados. Dionisio ${ }^{74}$ quiere subrayar que la iglesia de Roma no es la única fundada por los apóstoles. Eusebio de Cesarea transcribirá esta carta: "Porque Pedro y Pablo plantaron en nuestra Corinto y nos instruyeron de modo semejante; y también de modo semejante, tras haber enseñado juntos en Italia, dieron testimonio al mismo tiempo" (HE II 25,8).

Más información se puede obtener de las listas de obispos romanos. Sin embargo, éstas no aparecieron antes del tiempo de Hegesipo (c. 150 d.C.). De las listas no se puede determinar con seguridad el papel que desempeña Pedro en la vida de la comunidad. Los críticos suponen que la indicación según la cual Pedro habría sido obispo de Roma durante 25 años proviene de la imaginación o es fruto de una confusión. Dicha tradición no aparece antes de la mitad del siglo II. La celebración litúrgica (18 de enero y 22 febrero), que se refiere a la asunción de la cátedra episcopal de Pedro, aparece por primera vez en la primera mitad del siglo IV. Por tanto, los testimonios más antiguos del siglo II no indican que Pedro fuera obispo. Será, sin embargo, a principios del siglo III, cuando las "suposiciones" de la tradición se transformen en "hechos" de historia. Las indicaciones conservadas en Clemente, Tertuliano, Hipólito y en el material apócrifo y litúrgico se consideran como fuentes dependientes de la tradición que evidencian más bien el desarrollo que sufrió ésta. Así, en la segunda mitad del II se consolida la tradición de la predicación de Pedro en Roma, especialmente en las leyendas populares sobre el apóstol. El ejemplo del NT para tal actividad fue encontrado en la confrontación con Simón Mago (Hech 8,9-25; cf. HechPe).

74. C.P. THIEDE, Geheimakte 230s, subraya la fiabilidad de dicha información, afirmando que Pedro misionó antes que Pablo tanto en Corinto como en Roma, afirmando incluso: "Rom war das Gebiet des Petrus, nicht das des Paulus". 
¿Qué se puede decir de la tradición referente a la estancia de Pedro en Roma? Los estudiosos prácticamente afirman unánimemente que Pedro visitó Roma. Seguramente la obra más influyente con esta visión ha sido la de O. Cullmann. Pero también ha habido una minoría de autores que afirman lo contrario: las fuentes no apoyan la visión tradicional. H. Koch, H. Dannenbauer, J. Haller y sobre todo K. Heussi, pusieron en tela de juicio la estancia y la muerte de Pedro en Roma. El punto de partida para la reflexión de $\mathrm{K}$. Heussi es la afirmación de que Gal 2,6 presupone ya la muerte de Pedro (en torno al 55-56 d.C), por lo que toda la tradición de Pedro en Roma sería una "pura leyenda", dado que de los lugares clásicos usados para afirmar su muerte en Roma (1 Clem 5; Ign, Rom 4s; 1 Pet 5,13; Jn 21,18) no se concluye necesariamente esa suposición. Todo fue una creación de la comunidad romana dada la importancia que adquiría Pedro en el cristianismo ${ }^{75}$. Esta teoría no ha tenido seguidores y ha sido criticada duramente ${ }^{76}$. Más recientemente J.M. Michaels 77 ha vuelto a revivir la idea de que Pedro pudiera haber muerto de muerte natural a finales del siglo I, aunque no niega que este apóstol hubiera ido a Roma y que muriera probablemente allí.

Se puede aceptar, por tanto, que Pedro visitó Roma. Esta tradición es muy antigua y muy variada como para presuponer su total invención. Pero no se sabe cuándo vino a Roma, ni el tiempo de su estancia, ni la función de liderazgo que ejerció en esa comunidad 78 .

Pero no sólo se afirma la estancia de Pedro en Roma, sino que la patrística y los estudios modernos han defendido la opinión tradicional según la cual Pedro fue crucificado en Roma durante el reinado de Nerón (entre el 6467). Sólo las fuentes más tardías y menos fiables se preocupan del lugar de la crucifixión. Parece que hay un acuerdo general en estas fuentes, dado que coinciden en indicar que su crucifixión tuvo lugar cerca del Vaticano. Este dato topográfico puede ser fiable o derivar de la tradición según la cual Pedro murió en la gran persecución descrita por Tácito, llevada a cabo en las cerca-

75. War Petrus in Rom?, Gotha 1936; War Petrus wirklich römischer Märtyrer?, Leipzig 1937; Die römische Petrustradition in kritischer Sicht, J.C.B. Mohr \& Paul Siebeck, Tübingen 1954, 56 : "Daß tatsächlich von den Aposteln nur Paulus in Rom gewesen sein sollte, wäre für die Römer auf die Dauer ein schwer erträglicher Gedanke gewesen, denn Paulus gehörte eben doch nicht zu den nächsten Jüngern Jesu. Um so weniger vermochte man in Rom auf Petrus zu verzichten, als dessen Ansehen ständig wuchs und er in der Phantasie der Christen zum Weltapostel emporstieg, zum mystischen Hauptrepräsentanten des Apostolats".

76. Cf. O. Cullmann, Petrus 104s.

77. J.M. Michaels, 1 Peter (Word Biblical Commentary 49), Waco, Texas 1988, lv-lxvii.

78. Daniel Wm. O'Connor, Peter in Rome. The Literary, Liturgical and Archeological Evidence, Columbia University Press, New York - London 1969, 50. 
nías del Vaticano. Pero veamos los textos más significativos relacionados con su muerte.

El NT contiene algunas alusiones de la dirección que pudieron tomar los acontecimientos finales de la vida de Pedro. Jn 21,18-19 viene interpretado frecuentemente como una clara alusión a la muerte cruenta de Pedro, por lo que el EvJn testimonia que su último redactor conocía la tradición del martirio de Pedro (a finales del siglo I o principios del II). El "extender las manos" indica presumiblemente la muerte en cruz. En la literatura apócrifa de finales del II se desarrolló la idea de que Pedro había sido crucificado boca abajo por propio deseo. Ello corresponde al carácter edificante de dicha literatu$\mathrm{ra}^{79}$.

La literatura petrina también contiene alguna referencia a su muerte (1Pet 5,1.13). La "elegida" es la comunidad y el término "Babilonia" ha sido interpretado comúnmente como un nombre simbólico para Roma ${ }^{80}$. La imagen de Pedro como pastor (1Pet 5,1) indica cómo fue recordado Pedro en las últimas décadas del siglo I, lo cual hace referencia a Jn 21,1681. Por lo que 1Pet sugiere que las dos imágenes, de Pedro como "presbítero/pastor" y la tradición de su martirio fueron asociadas con la cristiandad romana a finales del siglo I.

Una ampliación de esa tradición aparece en 1 Clem 5,4: "Pedro, que tantos sufrimientos -no uno ni dos- tuvo que padecer por causa de una injusta envidia, y que, tras haber dado testimonio, marchó a la morada de gloria que le era debida. Y Pablo...".

Este pasaje ha sido considerado por muchos autores como el testimonio más antiguo y fiable del martirio de los dos apóstoles en Roma ${ }^{82}$. El martirio de los dos apóstoles aparece así como el punto de partida y el modelo del tes-

79. Eusebio, HE III 1,2. La razón aducida en ActPetr 38 para dicha forma de crucifixión es una especulación gnóstica.

80. Cf. Ap 17,5; ApBarsyr 11,1; 67,4; 4 Esr 3,1.28.31; también Billerbeck III 816. Ora Sib 5,158-160: "Llegará desde el cielo una estrella grande hasta el mar divino e incendiará el ponto profundo, la propia Babilonia y la tierra de Italia, por la que perecieron numerosos santos y fieles hebreos y el pueblo verdadero" (texto traducido por E.SUÁREZ DE LA TORRE, Oráculos sibilinos, en: Alejandro DíEz MACHo, Apócrifos del Antiguo Testamento Vol. 3, Cristiandad, Madrid 1982, 326). Este oráculo de la estrella destructora, formulado de manera bastante confusa, no ha encontrado una interpretación satisfactoria hasta el momento.

81. El elemento de guardar el rebaño (Jn 21,15-17) plantea diversas cuestiones: ¿Este mandato se refería únicamente a las actividades de Pedro en el primitiva comunidad de Jerusalén, tal y como lo encontramos en Hech? O ¿Pedro se convirtió en "pastor" de otras iglesias, después que fue obligado a abandonar Jerusalén?

82. Otto B. KNOCH, "Im Namen des Petrus und Paulus: Der Brief des Clemens Romanus und die Eigenart des römischen Christentums", en: ANRW II 27.1 (1993) 3-54, 40. 
timonio dado a Cristo frente a la envidia. Por el contrario, otros estudiosos son más cautos y creen que no se puede afirmar que el autor de 1 Clem conociera que Pedro había muerto mártir en Roma ${ }^{83}$. Todo el problema radica en la interpretación y traducción del término griego 'dar testimonio' ( $\mu \alpha \rho \tau v \rho \eta$ $\sigma \alpha \varsigma)$, si se ha de entender en sentido martirial, y por tanto se referiría al martirio sufrido, o si por el contrario indica que las muchas penalidades, que precedieron a la muerte, deben ser consideradas como testimonio. Presumiblemente es preferible esta última opción ${ }^{84}$. Es importante indicar, que Pedro viene nombrado en primer lugar, antes que Pablo.

En otro documento apocalíptico, la ascensión de Isaías $(3,13-4,19)$, se nos habla de un rey injusto, normalmente identificado con Nerón ${ }^{85}$. El contexto es una profecía de la venida de Beliar (el demonio) como el anticristo de los últimos días. La idea del adversario escatológico está unida a la tradición del regreso de Nerón. La tercera descripción que hace de este emperador es típicamente cristiana: perseguirá a la iglesia y matará a uno de los Doce ("entregar en manos"). Cuando se habla de uno de los Doce apóstoles, éste puede ser únicamente Pedro, pues Pablo no perteneció al círculo de los Doce. Además, no se puede referir a Pablo, dado que este apocalipsis cristiano lo ignora totalmente. Si no se menciona el nombre expresamente de Pedro, es porque el texto sigue el estilo apocalíptico de una determinación indirecta ${ }^{86}$. Que Pedro fue martirizado en Roma no viene expresamente afirmado, pero la referencia a la persecución de la iglesia romana por parte de Nerón y la asociación directa del martirio de Pedro con Nerón, probablemente implica que Pedro murió en Roma.

E. Peterson ${ }^{87}$ analiza el fragmento de Rainer del apocalipsis de Pedro 14: "Te he revelado e interpretado todo a ti, Pedro. Vete por tanto a la ciudad del oeste [de la prostitución] y bebe el cáliz que te he prometido de las manos de

84. J. GNILKa, Petrus 117; Horacio E. LoNA, Der erste Clemensbrief (KAV 2), Vandehoeck \& Ruprecht, Göttingen 1998, 160; otras opiniones en pag. 160, nota 5.

85. 4,2-3: "After it has come to its consummation, Beliar, the great prince, the king of this world who has ruled it since it came into being, shall descend; he will come down from his firmament in the form of a man, a lawless king, a slayer of his mother, who himself (even) this king will persecute the plant which the Twelve Apostles of the Beloved have planted; and one of the twelve will be delivered into his hand". Traducción C. DETLEF - G. MüLLER, "The Ascension of Isaiah", en Wilhelm Schneemelcher, New Testament Apocrypha, Vol II, James Clarke \& Co, Cambridge 1992, 609.

86. C. Clemen, "Die Himmelfahrt des Jesaja", en: ZWTh 24 (1896) 388-415 considera este pasaje como el testimonio más antiguo sobre el martirio de Pedro.

87. E. Peterson, "Das Martyrium des hl. Petrus nach der Petrus-Apokalypse", en: Frühkirche, Judentum und Gnosis, Rom u.a. 1959, 88-91. 
mi Hijo, quien está sin pecado, para que su trabajo... de destrucción sea santificado. Así comenzará su destrucción, tú sin embargo, te harás digno de la promesa..."88. El martirio en Roma está veladamente expresado. La ciudad de la prostitución (o del Oeste) se refiere a Roma, y el cáliz hace referencia a la muerte violenta (cf. Mc 10,39). Esta tradición resalta la figura de Pedro. Es la más antigua frente al paralelismo de Pedro y Pablo. Gnilka ${ }^{89}$ la considera como una tradición independiente que pudo haber surgido en los años 90.

Las razones del martirio de Pedro son confusas. Pudiera haber sido por la conexión con el gran fuego de Roma, o por negarse a ofrecer sacrificios rituales al emperador como símbolo de lealtad. Gnilka, tomando $1 \mathrm{Clem} 6,1 \mathrm{~s}$ y Tácito, Annales 15,38-44, llega a concluir que hubo dos persecuciones en Roma en tiempos de Nerón. En la primera sufrieron persecución algunos miembros cristianos y en la segunda, después del incendio de Roma (19 de julio de 64), fueron objeto de martirio una gran multitud (multitudo ingens), culpada no tanto por el incendio, cuanto por el odio contra el género humano (odio humani generis) ${ }^{90}$. Pedro habría padecido el martirio en el año 64, aunque sin determinar si en la primera o segunda persecución, y como lugar de ejecución sería el circo de Gayo y Nerón, en el ager Vaticanus ${ }^{91}$.

Pronto surgieron diversas leyendas en torno a la muerte de Pedro. En cuanto al modo del martirio se dice que Pedro fue crucificado con la cabeza hacia abajo (HechPe 35-40; cf. Eusebio HE 3,1). Probablemente se trata de una invención de nuestro autor, si bien por lo que se refiere a la crucifixión podría derivarse esa afirmación de Gal 2,19; Heb 6,6. En autores posteriores aparece el mártir como otro Cristo que padece el martirio (Orígenes, c.Celsum II 44; Tertuliano, De pudicitia 22). El detalle de la crucifixión de Pedro puede tener su origen en Jn 21,18-19. Podría ser una alusión velada a la crucifixión de San Pedro, pero no se puede demostrar con certeza. Otra leyenda, tomada de los Stromata de Clemente, narra un encuentro entre Pedro y su mujer, quien va a ser martirizada antes que él (HE 3,30). Una de las más populares viene descrita en los Hechos de Pedro, con la escena quo vadis, Domine? (HechPe 35), la cual podría depender de 2 Pe 1,14.

88. Cf. La traducción inglesa de C. Detlef - G. Müller, “Apocalypse of Peter”, en: W. Schneemelcher, New Testament Apocrypha, Vol II, James Clark \& Co Ltd, Cambridge 1992, 633.

89. J. GNILKa, Petrus 123.

90. H.W. TAJRA, The Martyrdom 29: "The expression odium humani generis would imply abandonment of one's political and religious duties toward the State and a willful separation from -and attitude of exclusiveness toward- the rest of society". P. KERESzTES, "Nero, the Christians and the Jews in Tacitus and Clement of Rome", en: Latomus 43 (1984) 411.

91. J. GNilKa, Petrus 121-122. Para Pablo, sin embargo, presupone el año 56 como año de su martirio. 
Las tradiciones narrativas referentes a Pedro sufrieron un mayor desarrollo a finales del siglo II. Los escritos anteriores, tales como el Apocalipsis de Pedro (Eth/Gk) o el evangelio de Pedro permanecen cercanos al material del siglo I. Las ampliaciones pueden provenir de otras tradiciones tales como la apocalíptica judía encontrada en 2 Ped o en apocalipsis de Pedro, sin que por ello altere la versión básica de las tradiciones petrinas del I. Donde la primitiva tradición guarda silencio, también el material de principios del II guarda silencio. Consiguientemente, no podemos afirmar con seguridad que Pedro fue martirizado, sino que tenemos unas vagas indicaciones que murió en Roma ${ }^{92}$. No se indican las circunstancias que envolvieron la muerte de Pedro. Sin embargo, la tradición posterior y, por tanto, más tardía, subraya el hecho del martirio de Pedro bajo el reinado de Nerón, por lo que podemos suponer que las primeras indicaciones apuntaban también hacia aquel acontecimiento como un hecho.

R.J. Bauckham ${ }^{93}$ hace un resumen del status quaestionis sobre el martirio de Pedro después de haber analizado los textos 1 Pet 5,1.13; Jn 13,36-38; 21,28-19; 2 Pet 1,12-15; 1 Clem 5,4; Ignacio de Antioquía, Smyrn 3; Rom 4,3; Ascensión de Isaías, 4,2-3; Apocalipsis de Pedro 14,4-6; Policarpo, Phil 9,1-2; Hechos de Pedro; Apocriphon de Santiago 5,9-20 (CG I,2); Dionisio de Corinto, en Eusebio, HE 2,25,8; Ireneo, Adv. Haer. 3,1,1; Canon de Muratori, líneas 25-31; Tertuliano, De Praescriptione 36. Concluye que se pueden considerar los siguientes acontecimientos como probablemente históricos: 1) Pedro murió mártir (Jn 21,18-19; 1 Clem 5,4; Ignacio, Smirn 3,2; Ascensión Isaías 4,3; Apocalipsis de Pedro 14,4; cf. 2 Pet 1,14): este hecho debió ser de conocimiento general en el cristianismo antiguo. 2) Fue crucificado (Jn 21,1819) 3) en Roma (Ap.Pedro 14,4; cf. Ascensión de Isaías 4,3; 2 Pet 1,12-15; para la estancia de Pedro en Roma, cf. 1 Pet 5,13; Ignacio, Rom 4,3; Papías, en Eusebio, HE 2,15.2) 4) durante el reinado de Nerón (Ascensión de Isaías 4,23; ApPet 14,4). 5) Su martirio fue interpretado en categorías apocalípticas en algunos círculos cristianos (Ascensión de Isaías, 4,2-3; ApPet 14,4). Otro argumento que aducen los estudiosos para afirmar su martirio en Roma es que ninguna otra ciudad se arrogó en la antigüedad ser el lugar de crucifixión de Pedro.

Es bastante cuestionable si se puede conocer algo más acerca del martirio de Pedro de las fuentes literarias. No existe una tradición segura que

92. Miguel RodríGuez, Tres apócrifos no gnósticos sobre Pedro (el apocalipsis de Pedro, el evangelio de Pedro y los hechos de Pedro), en: R. Aguirre Monasterio (ed.), Pedro 141-184, 181.

93. Richard J. BAUCKHAM, "The Martyrdom of Peter in Early Christian Literature", en: ANRW II 26.1 (1992) 539-595, aquí 588-589. 
conecte el martirio de Pedro con la persecución de Nerón ni una fecha segura durante el reinado de Nerón cuando tuvo lugar el martirio. La Ascensión de Isaías 4,2-3 relaciona el martirio con el persecución general de la iglesia, pero no significa que Pedro muriera durante esa persecución. El apocalipsis de Pedro 14,4, considera la muerte de Nerón como un castigo por el martirio de Pedro, por lo que podría sugerir que éste aconteció a finales del reinado de Nerón, aunque no necesariamente. Por tanto, hay que afirmar una ignorancia cronológica sobre la muerte de Pedro. Otras tradiciones que también se ponen en entredicho serían el hecho de que Pedro y Pablo murieron al mismo tiempo en Roma (Dionisio de Corinto, Ireneo); o que Pedro murió mientras Pablo estaba visitando España (canon de Muratori; última redacción de los Hechos de Pedro). Los descubrimientos arqueológicos de la colina Vaticana tampoco permiten afirmar mucho más de lo que indican los textos literarios ${ }^{94}$.

Narraciones dramáticas se incorporaron a los Hechos de Pedro. La figura de Pedro se vincula cada vez más a Roma. La ambigüedad del apóstol Pedro, tan remarcada en el NT, desaparece. Como mártir y apóstol, Pedro testifica abiertamente la verdad sobre Jesús. También pierde su papel de pobre pescador para entrar en la élite educada romana.

\section{La relación Pedro - Pablo en las tradiciones cristianas}

A pesar del conflicto de Antioquía, Pablo estima a Pedro y lo considera columna de la iglesia (Gal 2). Eduard Lohse se plantea la cuestión de lo que pensó Pablo sobre el apostolado de Pedro. La relevancia de Pedro para Pablo se limita específicamente a las referencias explícitas en 1 Cor y en Gal. La fórmula del credo que hereda y que Pablo transmite a sus comunidades, incluye a Pedro como el primer testigo de la resurrección (1Cor 15,5). En 1 Cor 15,311, la preocupación principal de Pablo es la cadena de testimonios que comienza con Pedro y concluye con su propia visión del Señor. Pablo fundamenta su apostolado en la misma base que Pedro y los Doce. No se trata de establecer un orden apostólico jerárquico. Lohse sugiere incluso que la doctrina paulina de salvación por medio de la fe prohíbe la distinción de perso-

94. H.G. ThüMmel, Die Memorien für Petrus und Paulus in Rom. Die archäologischen Denkmäler und die literarische Tradition (Arbeiten zur Kirchengeschichte 76), de Gruyter, Berlin 1999, 97: "Vielmehr stimmen das literarische Zeugnis und das Ergebnis der Ausgrabungen darin überein, daß vor der 2. Hälfte des 2. Jahrhunderts nichts nachweisbar ist, was auf ein Petrusgedenke hinweisen könnte. $\mathrm{Da}$ auch die Todestage der Apostel nicht überliefert sind, spricht ebenfalls gegen eine Kulttradition". 
nas por haber sido llamadas unas antes que otras, como tampoco se puede hacer distinción entre los judíos, que primeramente escucharon la palabra de Dios, y los gentiles. Pablo no criticaría a Pedro en la polémica de los partidos en Corinto (1 Cor 1,12). Por tanto, Lohse95 concluye: no hay indicaciones de parte de Pablo para afirmar una ruptura de relaciones entre los dos apóstoles. Las cartas paulinas muestran que el prestigio y la autoridad de Pedro ya había sido reconocida por los cristianos más allá de las áreas de SiriaPalestina, en las que éste había trabajado. No sabemos lo que los gálatas o los corintios sabían sobre Pedro. Pero la retórica paulina deja entrever que Pablo no podía afirmar su propia autoridad como apóstol, ni siquiera en las iglesias que él había fundado, sin tener en cuenta su relación con otros apóstoles, y especialmente con Pedro. El empleo de la figura de Pedro, como figura autoritativa en una argumentación para validar la misión paulina, indica su importancia dentro de las comunidades cristianas de la diáspora.

Algún autor cree que Pedro perdió ineludiblemente su relevancia en comunidades paulinas, no a causa del conflicto de Antioquía, sino mucho más tarde, y eso a pesar de las coincidencias importantes en temas teológicos fundamentales. Este fenómeno se puede explicar tal vez históricamente. En lugar de considerar una pérdida unilateral de la importancia de Pedro, se debería hablar de una división de círculos autoritarios eclesiales en la segunda mitad del siglo I. Pablo se convertirá en el apóstol por excelencia de sus comunidades. Al mismo tiempo, éste pierde importancia en Oriente, especialmente en Siria. Allí se incrementará la autoridad de Pedro. Aparece así el significado de su nombre como piedra de la iglesia (Mt 16,18s) ${ }^{96}$.

El hecho de que una carta petrina (1 Pet) esté dirigida a un área (Asia Menor), en la que tanto las tradiciones paulinas como joánicas eran importantes, sugiere que la importancia de Pedro para la gran iglesia fue reconocida tempranamente. Por tanto, 1 Pet debe ser considerada como un testimonio

95. "St. Peter's Apostleship in the Judgment of St. Paul, the Apostle to the Gentiles: An Exegetical Contribution to an Ecumenical Debate", en: Gegrorianum 72 (1991) 419-435.

96. Martin KARRER, "Petrus im paulinischen Gemeindekreis", en: ZNW 80 (1989) 210- 231

97. Terence V. SMITH, Petrine Controversies in Early Christianity. Attitudes towards Peter in Christian Writings of the First Two Centuries (WUNT II 15), J.C.B. Mohr, Tübingen 1985, 154: "The fact that the letter was sent to areas associated with the missionary efforts of Paul may indicate the existence of a rival, Petrine mission in the same area. In this way, 1 Pet is recognized as "Petrine" in the sense that it stems from a group, perhaps based in Rome, concerned to venerate Peter's memory and disseminate traditions associated with him".

98. T.V. SMITH, Controversies 101: "Hence, whether the adoption of Peter as the chief apostolic authoriy was provoked by the opponents' denigration of him or by their own attempts to claim him as a Gnostic authority, 2 Peter would indicate that the second century witnessed controversies between rival Christian groups, and that part of such disputes was concerned with the standing of the Peter-figure". 
para la universalización de Pedro como líder de la iglesia ${ }^{97}$. El evolución de la figura de Pedro viene reflejada en 2 Pet ${ }^{98}$.

Si nos fijamos en el desarrollo de las tradiciones sobre Pedro en los dos siglos siguientes, nos encontraremos todas las variantes sugeridas por las tradiciones canónicas. Se deben distinguir tres grandes corrientes dentro de la iglesia de finales del s. I y durante el s. II, que han dejado su impronta dentro de las obras literarias en las que de alguna manera se hace referencia a Pedro y a su autoridad, de manera explícita o implícita.

1) La primera podría denominarse corriente "oficial" o romana, según la cual el obispo de Roma en cuanto sucesor de Pedro habla y actúa con autoridad propia. Serán escritos judeocristianos los que resalten las diferencias entre Pedro y Pablo. En algunos círculos judeocristianos, Pablo será el archi-herético por excelencia. Pablo no es nunca citado explícitamente en las seudoclementinas, pero hay alusiones suficientemente claras a él, de un antipaulinismo furibundo ${ }^{99}$ y se intenta desacreditar a los que consideran a Pedro como sucesor de Pablo en la misión a los gentiles. Esta literatura muestra un distanciamiento voluntario respecto del apóstol Pablo y nos informa que hubo personas que le consideraron un gran enemigo, porque entendían que predicaba un "falso evangelio", en desacuerdo con las enseñanzas de los demás apóstoles. Las seudoclementinas testimonian que algún grupo judeo-cristiano reivindicó el papel de Santiago y Pedro frente al de Pablo. Esto significa que probablemente una segunda rama de la tradición petrina, que intentaba relacionar a Pedro con Santiago, estuvo vinculada al judeo-cristianismo.

En los Hechos de Pedro, éste aparece como el segundo fundador de la iglesia de Roma, más exactamente, como su verdadero fundador, después de que ésta fuera destruida completamente por Simón Mago, a excepción de unos siete cristianos que se habían refugiado en el "hospitium Bithynorum" y de otros que habían huido de la ciudad. Así se convierte Pedro en el verdadero fundador de la iglesia de Roma. Para el autor de los HechPe es Pedro el personaje principal de la iglesia romana, por tanto, más importante que Pablo. El autor parece querer conjugar las dos tradiciones, según las cuales Pedro y Pablo han fundado la Iglesia de Roma y han padecido el martirio allí

99. Conocido es el fragmento antipaulino: "Entonces comprendí que revelación es aprender algo sin que alguien te lo enseñe, sin visión ni sueño" (Hom XVII 18,2)... "Tú te has opuesto como adversario a mi, que soy la piedra firme, el fundamento de la iglesia. Si no fuerami adversario, no me criticarías ni difamarías mi predicación, haciendo que no sea creído en aquello que oí directamente del Señor" (ib. 19,4s). Cf. Jordi SÁNCHEZ Bosch, "Santiago, Pedro y Pablo en las Seudoclementinas", en: M. Perroni - E. SAlMANn (eds.), Patrimonium Fidei. Traditionsgeschichtliches Verstehen am Ende?, FS. M. Löhrer - P.R. Tragan, Roma 1997, 547-573, 558-564. 
en tiempo de Nerón, pero a la vez trata de establecer una jerarquía: Pedro es el apóstol más importante de la comunidad cristiana de Roma.

En la literatura de la tradición judeocristiana, Pedro se dedicará a combatir en su misión a Simón/Pablo, con el fin de deshacer la labor "engañosa y destructiva" que realizaba en las comunidades Simón/Pablo ${ }^{100}$. Pablo es censurado con frases duras. Pedro, por el contrario, es considerado como la roca firme y el fundamento de la iglesia. No cabe duda de que en estos ambientes existe una fuerte polémica contra Pablo y sobre todo el recuerdo que ha dejado el incidente de Antioquía y la actitud de éste con respecto a la ley.

Durante la tercera generación cristiana hacen su aparición una serie de escritos que reclaman la autoridad de Pedro: el evangelio de Pedro, el kerigma de Pedro, 2 Petr y el apocalipsis de Pedro. En otros escritos de esta época (1Clem y las cartas de Ignacio de Antioquía) se reclama directa o indirectamente dicha autoridad ${ }^{101}$. Todos estos escritos están relacionados con Siria o Roma, y pueden ayudarnos a esbozar la trayectoria de la tradición petrina en el periodo post-apostólico.

2) Sin embargo, la mayoría de los escritos de esta época relacionan a Pablo con Pedro y los convierten en autoridades de orden eclesiástico en la iglesia de Roma. Ellos son presentados como misioneros mártires heroicos, unidos en su testimonio por el evangelio así como en su predicación. Este fenómeno comenzó a finales de la segunda generación cristiana con 1 Pe y la $1 \mathrm{Clem}$. Ya hemos visto que a finales del siglo II, Dionisio de Corinto trata a los dos apóstoles como figuras paralelas. Pero el testimonio más elocuente de esta vinculación entre Pedro y Pablo, como supremas autoridades de la iglesia católica lo encontramos en las cartas de Ignacio de Antioquía. Especialmente hay que destacar la carta a los romanos 4,3, donde se muestra que el paralelismo entre Pedro y Pablo ya se ha convertido en una rutina. "Mientras que otros pasajes sólo hablan de Pedro, mientras en $1 \mathrm{Clem}$ enumera los nombres de Pedro y Pablo uno junto a otro, están los dos apóstoles en Ignacio ciertamente intrínsecamente unidos"102. El que se nombre conjuntamente a ambos apóstoles no es fácilmente explicable, si tenemos en cuenta su enfrentamiento en Antioquía (Gal 2,11-14) y la reivindicación de la autoridad de Pedro frente a la de Pablo, hecha por algunos grupos judeo-cris-

100. Cf. Rec III, 65; X 54; Hom II 17. Cfr. Fernando CuENCA, "Pedro en la tradición judeocristiana", en: R. Aguirre Monasterio (ed.), Pedro 223- 233.

101. Santiago GuiJarRo, "Trayectoria" 25.

102. S. GuIJARRo, "Trayectoria" 26. Ignacio de Antioquía asociaba también a los dos apóstoles Pedro y Pablo, inseparablemente unidos, a los destinos de la iglesia: "No os doy órdenes como lo hacían Pedro y Pablo: ellos eran apóstoles, mientras que yo soy un condenado; ellos eran libres, mientras que yo hasta el presente, soy un esclavo" (Ign Rom 4,2-3). 
tianos en Siria por la misma época. Ignacio menciona a Pedro y Pablo unidos, porque estaban en una relación especial con la comunidad de Roma. Finalmente, la alusión a Pablo y a sus cartas en 2Pet 3,15-16 es un dato más de la relación que se estableció entre la tradición paulina y la petrina.

Ireneo ${ }^{103}$ pone en relación directa la fundación de la comunidad romana con Pedro y Pablo. Su martirio sin embargo no se menciona. Ireneo tenía que saber que la comunidad de Roma ya existía antes de la llegada de Pedro y Pablo. ¿Cómo pudo escribir eso a Roma? Seguramente defendía la teoría de que sólo con la aparición de los apóstoles en Roma adquirió la comunidad una verdadera entidad. El presupuesto de que Pedro y Pablo habían muerto en la persecución de Nerón ayudó sin lugar a dudas a relacionar a los dos apóstoles en la tradición. Tertuliano, en la misma época que Ireneo, pero en Cartago, habla de la iglesia de Roma como la iglesia afortunada en la que los apóstoles derramaron, junto con su sangre, toda su doctrina (cfr. De praescriptione 36, 1-3) ${ }^{104}$. El obispo Firmiliano de Cesarea (hacia el año 255) escribe a Cipriano y sigue haciendo referencia a esta relación de ambos apóstoles con la iglesia de Roma.

Se ha constatado ${ }^{105}$ que únicamente las fuentes griegas hablan de Pedro y Pablo siempre relacionados con la comunidad de Roma. Ejercen conjuntamente su autoridad en la comunidad en Roma. En un documento interesante, la lista de los obispos romanos de Epifanio de Salamina (320-403), se deja traslucir la idea de que Pedro y Pablo dirigieron la iglesia de Roma, nombraron obispos sucesores a Lino, Cleto y Clemente y sufrieron el martirio en el mismo año. Epifanio sigue la tradición de las fuentes griegas, según la cual

103. "Pero, como sería muy prolijo enumerar las sucesiones que se han producido en todas las iglesias, hablaremos de la mayor de ellas, la más conocida y la más antigua de todas, fundada y constituida en Roma por los dos gloriosísimos apóstoles Pedro y Pablo... Habiendo así fundado y edificado la Iglesia, los bienaventurados apóstoles transmitieron su administración episcopal a Lino, al que Pablo menciona en sus epístolas a Timoteo. A éste le sucedió Anacleto, tras el cual el episcopado recayó en Clemente, el tercero después de los apóstoles, que conoció a los propios apóstoles y habló con ellos...En tiempos de este Clemente, y con ocasión de una muy viva discusión entre los hermanos de que estaban en Corinto, fueron escritas importantes cartas por la iglesia de Roma..." (Adv. Haer III, 3,1-2).

104. Tertuliano habla también del apóstol Juan.

105. F.R. Gahbauer, "Petrus und Paulus in Rom. Sprachlich und ekklesiologisch bedingte Tedenzen zugunsten des Petrus oder Paulus in den Texten (2.-4. Jh.)?”, en: Pietro e Paolo. Il loro rapporto con Roma nelle testimonianze antiche. XXIX Incontro di studiosi dell'antichità cristiana, Roma, 4-6 maggio 2000, (Studia Ephem. August. 74), Institutum Patristicum Augustinianum, Roma 2001, 161: "Petrus und Paulus werden also wie vorher schon in der griechischen so auch in der lateinischen Version zusammen gesehen und somit eine Tendez aus dem griechischen Osten übernommen. Die Petrustendenz ist in der lateinischen Version stärker als in der griechischen". 
Pedro y Pablo formaban un binomio apostólico. Eusebio de Cesarea habla igualmente de Pedro y Pablo como obispos de Roma, aunque nombra a Pablo antes que a Pedro. Ambos testimonios, de Eusebio y Epifanio, parecen ser los únicos que conocen a Pablo junto con Pedro como obispos de Roma.

En el concilio de Arlés se considera a la iglesia local de Roma fundada en la sangre de los apóstoles Pedro y Pablo. La tradición que aparece en San Ireneo, y que se desarrolló entre los siglos IV y V, ve el origen de la iglesia romana $\mathrm{y}$, consiguientemente, de su episcopado y de su cathedra en los dos apóstoles, unidos por un lazo único e irrompible, como si no formaran más que una sola y única persona. Unificación que ya se daba en la liturgia, que celebraba el mismo día, 29 de junio, el martirio de ambos apóstoles; y no tanto como se dirá más tarde al tratar de explicar la anomalía de esta única celebración- porque hubieran recibido el martirio el mismo día, sino más bien porque se habían convertido en una sola cosa en la fundación de la iglesia de Roma.

Del mismo modo, los textos litúrgicos han vinculado las fiestas de estos dos apóstoles. Cabe destacar el Deposito Martyrum, escrito en torno al 310, con una lista de fiestas con sus particulares patrones que se celebran en Roma: "III Kal. iul. Petri in Catacumbas et Pauli Ostense, Tusco et Basso consulibus" (refiriéndose al año 258). El Martyrologium Hieronymianum informa también de la fiesta conjunta del 29 de Junio. La elección del 29 de Junio para celebrar dicha fiesta no se debe a que fuera el día de la muerte de los apóstoles, sino que dicha fiesta cristiana intenta suplantar a la celebrada en Roma en Quirinus in colle: Se conmemoraba la fundación de Aedes Quirini, en honor de los fundadores de Roma. Esta interpretación está apoyada por un sermón de León Magno para ese día, en el que dice: "Los apóstoles han protegido mejor la ciudad que ésos que construyeron sus murallas" (Epístola 82, "In natali Apostolorum"). Se supone que la elección de esa fecha fue arbitraria y así se presenta como una fecha lógica para la conmemoración de los que se suponían eran los fundadores de la comunidad de Roma.

La tradición desarrolló esta vinculación entre los dos apóstoles en la literatura martirológica tardía, creando el encarcelamiento conjunto (prisión de Mamertinum con la inscripción: prisión de los SS. Apostoles Pedro y Pablo en el Foro Romano). Es muy improbable que Pedro y Pablo hubieran estado juntos en prisión. Es más bien Pedro, y no Pablo, quien es asociado con la prisión Mamertinum. Pedro juega un papel mucho más importante en la Passio SS. Processi et Martiniani Mart. que Pablo, quien es una figura secundaria. Mientras que el encarcelamiento de Pedro está muy enraizado en la antigua iglesia

106. U.M. FAsola, Pietro e Paolo a Roma: orme sulla roccia, Roma 1980, 57; H.W. TAJRA, Martyrdom 101-102 
romana, la prisión de Pablo en Roma -aunque mejor atestiguada históricamente- fue perdiéndose gradualmente de la memoria de la iglesia romana ${ }^{106}$.

3) Algunos grupos gnósticos utilizarán la figura de Pedro ${ }^{107}$, pero dado que no nos aporta nada significativo para nuestro estudio, nos los trataremos.

\section{Conclusión}

Es ahora el momento de hacer una valoración de los datos anteriormente recogidos e intentar responder, en la medida de lo posible, a las preguntas planteadas al inicio. En primer lugar, no podemos afirmar que haya habido un conflicto entre Pedro y Pablo en la comunidad de Roma, en el que Pedro hubiera salido vencedor; desbancado la posición de Pablo dentro de una comunidad con mayoría de pagano-cristianos. Las fuentes no nos permiten ni afirmar ni negar que se hubieran encontrado los dos apóstoles en Roma, pero probablemente el enfrentamiento en Antioquía fue la última ocasión en que se encontraron. Otro encuentro es poco probable, ni siquiera en Roma ${ }^{108}$. Las fuentes literarias (Pablo, Lucas o los textos posteriores dignos de crédito) no dejan entrever un conflicto entre ambos en Roma.

La tradición latina occidental, sin embargo, resaltó desde muy antiguo la autoridad de Pedro incluso sobre Pablo, a pesar de que Pedro no había dirigido ninguna carta a esa comunidad ni tenía los colaboradores de Pablo en Roma (cf. Rom 16). Incluso, en la tradición oriental donde aparece indicada la unidad de los dos apóstoles, viene mencionado casi siempre Pedro en primer lugar. ¿A qué se debió este hecho?

Una respuesta a dicha cuestión podría ser el hecho de que Pedro hubiera fundado la primera comunidad romana y, por tanto, habría gozado siempre de una estima particular. Pero ya hemos indicado que esta posibilidad está excluida, pues es poco probable que Pablo hubiera "fundado" sobre cimientos ajenos. No obstante, la relación constante de Pedro con Roma en las fuentes, hace pensar que Pedro tuvo que tener algún contacto especial con Roma de forma que la tradición posterior lo recordó como el verdadero fundador o dirigente de la comunidad. La estancia de este apóstol es casi segura en Roma, pero eso no explicaría el papel relevante que la tradición le otorgó, dado que Pablo también habría visitado dicha comunidad.

107. Gonzalo Aranda, El apóstol Pedro en la literatura gnóstica, en: R. AgUIRRE MonASTERIo (ed.), Pedro 205.

108. J. GNILKa, Petrus 106. 
La diferencia entre Pedro y Pablo no se debe buscar exclusivamente en que Pedro había sido el primer discípulo elegido por Jesús, ni en su relación especial con el Señor, ni en haber sido probablemente el primer discípulo al que se le apareció Cristo, ni en haber sido una de las columnas de la primitiva iglesia de Jerusalén (Gal 2). Por supuesto que estos acontecimientos jugaron un papel importante, pero creo que tuvo que haber algún hecho histórico decisivo para asociar para siempre la figura de Pedro con Roma en detrimento de la figura paulina. Este hecho debió ser sin lugar a dudas el martirio que Pedro sufrió en la ciudad que es reconocida cơmo centro del imperio. Pablo, por el contrario, pudo haber muerto en Roma, pero no creo que como consecuencia de una persecución contra los cristianos, sino más bien por instigación de los mismos cristianos o de muerte natural. Claro está que éste también dio testimonio con su evangelización, pero no de la misma forma que Pedro, quien entregó su vida. Así se podría explicar el reconocimiento de la autoridad de Pedro. Roma absolutizó a Pedro y vio en él al único portador de autoridad de dicha comunidad. En los siglos III-V, los obispos romanos se considerarán sucesores y herederos de Pedro, pero en ningún documento se nos indica que fueran sucesores de Pablo.

Pero no por eso Roma se olvidará de Pablo. Habrá un intento de relacionar la tradición petrina y la paulina, que a finales del siglo I d.C. es un hecho ya en Roma como se advierte claramente en 1 Clem. La tradición de que Pedro y Pablo murieron en Roma en tiempos de Nerón jugó un papel importante en el siglo II para la unidad de ambas tradiciones apostólicas. Ante la falta de información fidedigna sobre la muerte de Pablo, pronto surgió un deseo de olvidar las circunstancias de su muerte relacionándolo a Pedro, y la misma tradición presentó su muerte como un martirio, vinculando en la medida de lo posible la tradición paulina con la petrina. En ello influiría, además de la importancia adquirida del mensaje y de las cartas paulinas, el hecho de que las fuentes griegas intentaran revalorizar a Pablo frente a Pedro hasta hacerlos semejantes en rango e importancia dentro de la comunidad de Roma. Oriente consideró a Pedro y a Pablo como una unidad o pareja de apóstoles, lo que posteriormente fue recibido y asumido por los romanos $^{109}$. Es de suponer, que las presiones y hostilidades externas en tiem-

109. F.R. Gahbauer, "Petrus" 163, concluye, "dass vorwiegend lateinische Quellen und nur ein bis zwei griechische einzig über Petrus und seine Stellung in Rom berichten, ohne den Paulus $\mathrm{zu}$ erwähnen. Jedoch nicht nur vorwiegend lateinische und nur wenige griechische Quellen des zweiten bis vierten Jahrhunderts wissen von der Bedeutung der Apostel Petrus und Paulus in Rom, auch für orientalische Zeugnisse trifft dies zu". 
po de persecución unificaron en parte las distintas tendencias cristianas en función del bien común.

Pronto comenzaron a surgir leyendas referentes tanto a un apóstol como a otro. No es cuestión aquí de tratar si las leyendas de un apóstol (Pedro) influyeron en las de Pablo, o surgieron independientemente unas de otras siguiendo un topoi narrativo fijo en las vidas de los apóstoles, pero se constata la aparición a comienzos del siglo II de la escena de Quo Vadis del apóstol Pablo (contenida en el Acta Pauli) en paralelismo a la escena de Pedro.

Es en esta época cuando el martirio juega un valor muy importante en las comunidades cristianas. Por eso no sorprende que la leyenda narre la decapitación de Pablo, dado que según la supuesta ciudadanía romana de Hechos, no podía morir de otra forma, si se le quería hacer dar testimonio martirial, al igual que Pedro. En las fuentes griegas, Eusebio y Epifanio de Salamina, Pablo será designado junto con Pedro como obispo de Roma. Epifanio y Eusebio escribieron unos 150 años más tarde que la composición del Acta Pauli. Éstos reconocieron y afirmaron el significado e importancia de Pablo como apóstol y mártir, comparable al significado de Pedro. Correspondientemente Pablo tiene también su experiencia de Quo vadis, y su martirio es tan importante como el de Pedro, ya que éste tuvo lugar por una aparición del mismo Cristo, quien le anunció su inminente muerte en Roma.

Lo mismo se puede comprobar en la veneración litúrgica de los apóstoles. En Roma ya se veneraba el sepulcro de Pedro desde el año 200. ¿Cuándo se comenzó a venerar a Pablo en Roma? La fiesta de Pedro y Pablo se celebraba originalmente en Oriente el 29 de junio como fiesta de todos los apóstoles. Los apóstoles más importantes tenían conjuntamente su propia fiesta en la octava de navidad. Esta fiesta común de los apóstoles fue aceptada en Roma, pero restringida a sólo dos de ellos. Y como tal se constata por primera vez en el año 258. La propagación de la veneración de los mártires a mediados del siglo III explica el periodo de su inauguración o aparición. La iglesia se apropió de la fiesta pagana de Rómulo y Quirino, celebrada el 29 de Junio, fundadores de Roma, y la sustituyó por una nueva dedicada a los dos apóstoles, "fundadores" o consolidadores de la comunidad romana. Ahora la comunidad romana tenía también a sus "Rómulo y Quirino" cristianos. Los diversos lugares romanos donde se pensaban que estaban las reliquias de Pedro o habían tenido una relación especial con él, adquirieron gran importancia.

El motivo de una tradición apostólica unificada expresada mediante la pareja de mártires, evocaba otro tema importante en tiempos romanos más tardíos. La preocupación por la concordia y solidaridad es expresada frecuentemente tanto en discursos cívicos como religiosos. Aunque los cristianos se contentaban anteriormente con un único santo patrón o mártir, las iglesias 
en el perido romano tardío preferían las parejas. Las profundas divisiones en la ciudad de Roma en el siglo III haría de la fiesta de San Pedro y San Pablo como un recuerdo o admonición del ideal de armonía. Pero en el siglo IV, la tumba de Pedro en la colina Vaticana simbolizó un nuevo sistema de patronazgo de la iglesia ${ }^{110}$.

Con esta hipótesis no estamos afirmando el Primado de Pedro en Roma, sino simplemente intentando explicar el hecho de que una comunidad filopaulina optara por considerar a Pedro como su fundador y su patrón en la tradición posterior. La tendencia a vincular a Pedro y Pablo no consiguió que desaparecieran o se erradicaran otras corrientes minoritarias contrarias a esta relación, como podían ser ciertos grupos judeocristianos.

\author{
DAvid Álvarez Cineira \\ Estudio Teológico Agustiniano \\ Valladolid
}

110. Peter BRown, The Cult of the Saints: Its Rise and Function in Latin Christianity, Chicago, University Press 1981, 96s. 